\title{
CONTRIBUCIÓN AL ESTUDIO DE LA ESTÍLISTI- CA DE GUSTAVO ADOLFO BÉCQUER
}

\author{
Determinación del propósito
}

Cada día aumenta el interés hacia Gustaro Adolfo Bécquer, considerado hoy como $\mathrm{el}$ poeta máximo del siglo xix o, al menos, el que está más vivo y conserva valor más actual para nosotros en unión cle la gran poetisa gallega Rosalía de Castro. Los trabajos sobre Ciustavo Adulfo se han multiplicado en los íltimos tiempos. A investigadores y críticcs como Dámaso Alonso, Rafael de Balbín, Gamallo Fierros, Paul P. Rogers, Eddmund L. King se les deben trabajos importantes, bien por el hallazgo de nuevas noticias biográficas y textos desconocidos, bien por las precisiones y estudios de las relaciones literarias entre el gran pocta sevillano y sus contemporáneos. Nosotros mismos hemos laclo a la estampa, por primera vez en nuestro tiempo, el teatro de Bécquer, que, aunque escrito en colaboración y publicado con seudónimos, si no alcanza la altura literaria de sus Leyendas y sus Rimas, no carece de interés, como cuanto atañe a tan alto poeta. José Pedro Díaz ${ }^{1}$ escribió cl primer libro importante de conjunto sobre Bécquer de carácter científico $y$, posteriormente, Heliodoro Carpintero ${ }^{2}$ ha levantado la punta del velo que ocultaba, en parte, la tragedia íntima del autor de las Cartas desde mi celda. Sería injusto omitir los nombres de Franz Schneider, W. S. Hendrix y Jesús Domínguez Bordona ${ }^{3}$; sus trabajos

1 Josí Pledro Dínz, Gustavo Adolfo Bécquer. Tida y poesia. Segunda edición, Maclrid, Gredos, 1958.

2 Inilonoro Caririntiro, Bécquer de par ell par, Madrid, Insula, 1957.

- I. SCInisidir, Gustavo Adolfo Bécquer as Poela and his linowledge of Ilcinc's J.icler. Modern IJhilology, x922, XIX, pp. 242-256; W. S. MU:INDRIX, Las rimas de Bécquer y la influencia de Byron. Bolelin de la lieal Acallemia de la

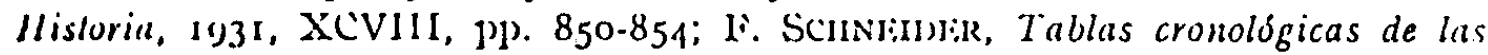
obras de Citustuvo Adolfo Becquer, RFE, 1929, XVI, 1p. 389-399; J. Dovificur:z Homuxs, lil aulógrafo de las Rimas de Décquer, RFI: 1928, $\mathrm{x}, 1 \mathrm{p}$. 173-179. 
no son ya tan recientes como los anteriormente citados, pero con ellos se inicia el estudio verdaderamente cientffico del inmortal escritor. Nuestro propósito es el de contribuir al conocimiento del estilo de Gustavo Adolfo Bécquer estudiando algunas de sus características y, sobre todo, realizar un intento de penetrar en el momento misino de la creación literaria teniendo presentes dos elementos importantes: la existencia de autógrafos que no nos presentan la obra becqueriana en su estado definitivo, sino en plena elaboración y las relaciones entre determinadas rimas y algunos pasajes de sus obras en prosa.

El presente estudio va dividido en tres partes. La primera de ellas, a su vez, se divide en tres apartados. El primero se consagra a un breve cotejo del estilo de Bécquer en sus obras en prosa y en sus rimas, estudio que podría ser fácilmente ampliado y convertirse en una monografía independiente. El segundo va dedicado a los epitetos en las obras en verso y prosa de Gustavo Adolfo; es, asimismo, muy breve, por existir sobre el tema otros trabajos. El tercero está encaminado a examinar la existencia de correlación y paralclismo en las famosas rimas. Todos ellos tienen por finalidad demostrar que el Bécquer en verso procede más por eliminación que por acumulación de elementos artísticos y que la estructura de sus rimas, al menos de algunas de ellas, fue sabiamente estudiada por el autor y no consecuencia de arrebatos espontáneos e irreflexivos.

Fin la segunda parte de nuestro estudio se realiza un análisis minucioso de dos manuscritos autógrafos que representan estados intermedios en la elaboración de las rimas LXXIII y LXXVI. Juzgamos interesante observar los tanteos $\mathrm{y}$ vacilaciones que aparecen en estos borradores que representan dos composiciones en plena elaboración. Observar qué ideas surgían en la mente del poeta, cuáles eran admitidas y cuáles rechazadas y cómo, entre rectificaciones y tanteos, se llega a la forma definitiva y cuajada que será inmortal.

La tercera parte, mucho más extensa que las anteriores, pone frẹte a frente varios pasajes de las obras en prosa de Bécquer y otras tantas de sus rimas entre las cuales hay evidente relación. El parentesco puede estar en las ideas, en el vocabulario y en las imágenes. No es nuevo el hallazgo de estas concordancias becquerianas, pero sí lo es el intento de ahondar más en el estudio de las mismas. El problema fundamental es el de la prioridad entre ellas y ésta no siempre es fácil de precisar, pues no se conoce, a veces, la fecha de redacción o, en su caso, de publicación de los diversos textos. Hemos intentado disponerlos por orden cronológico tanto como nos ha sido posible, teniendo en cuenta los datos conocidos. Lil problema es fundamental para determinar si una intui- 
H

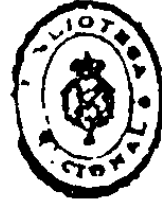

Silbo de tos gurriomes

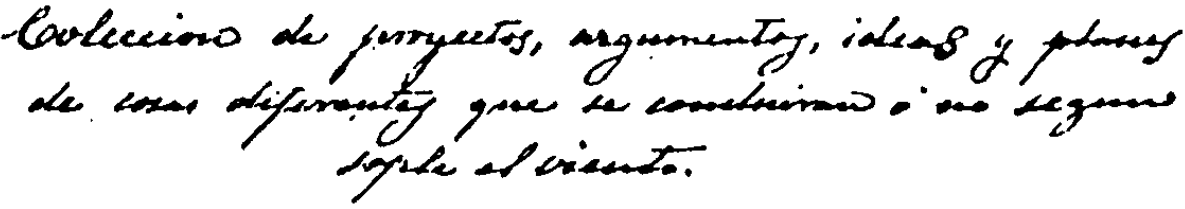

Qu

Gustavo Rdolfo Clandio O. SPeequer.

3868

Madiud $17 g^{\text {no }}$. 


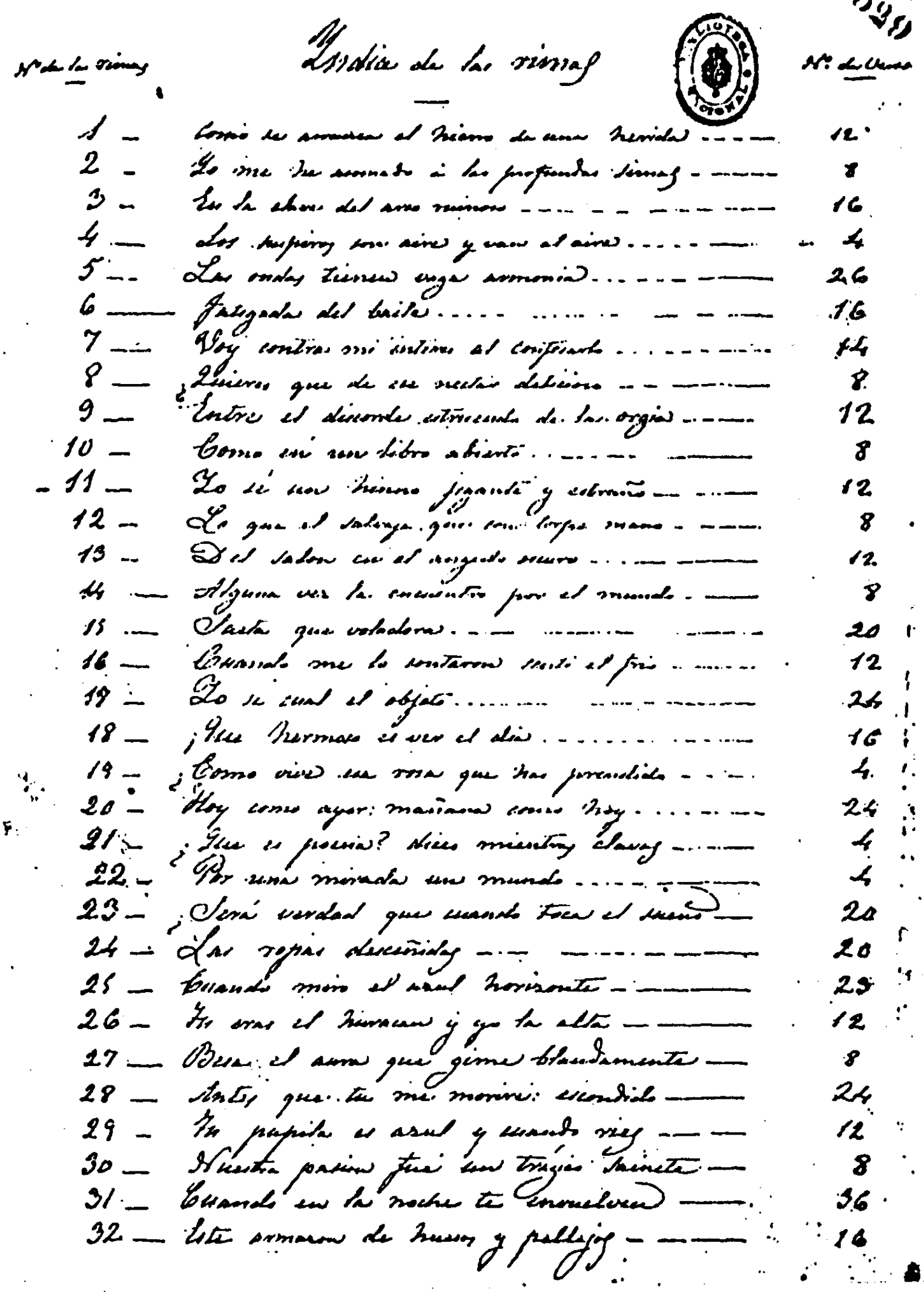




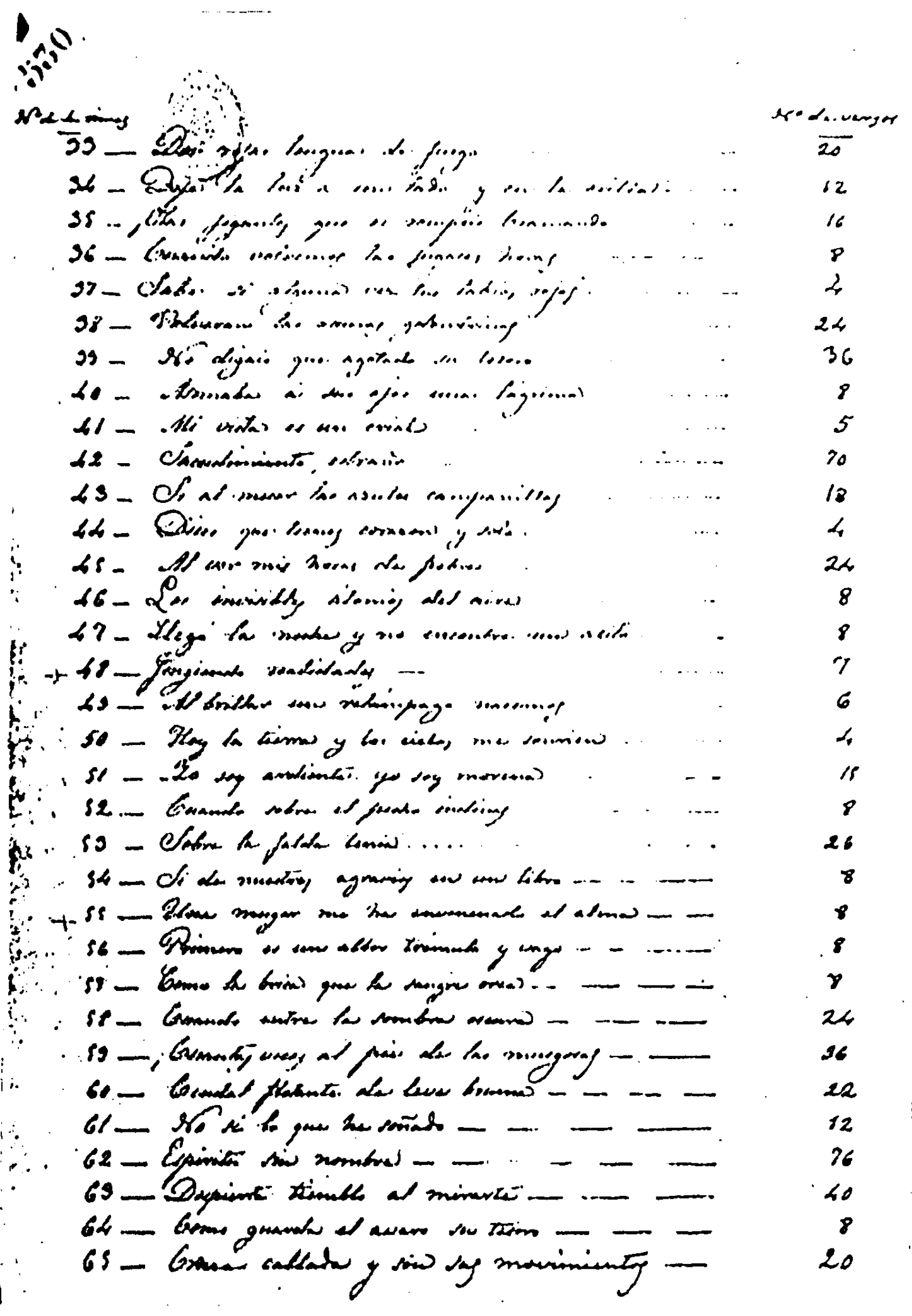


$\dot{H}+$ Laming

Ne denengen

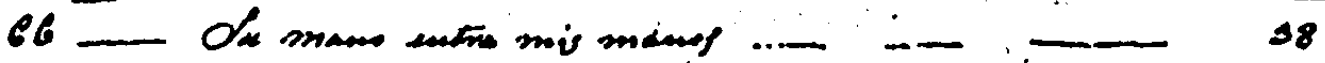

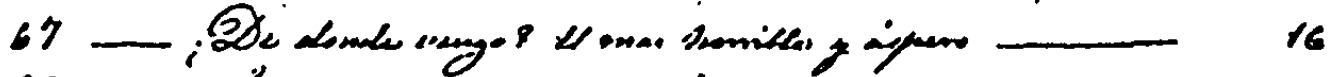

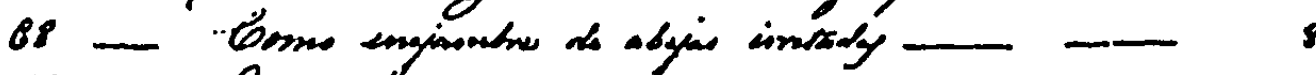

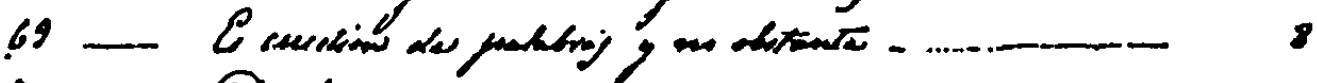

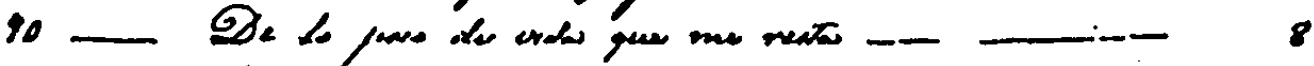

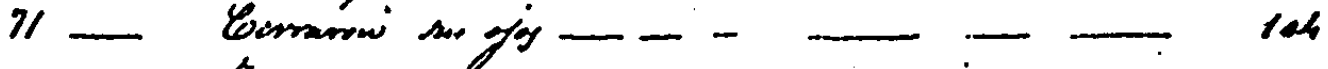

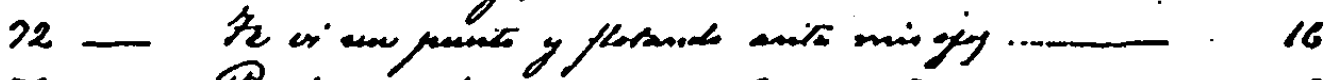

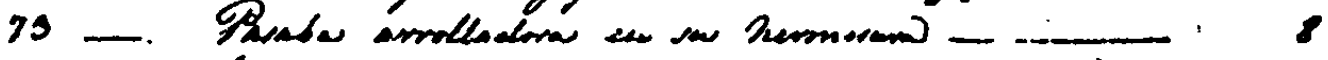

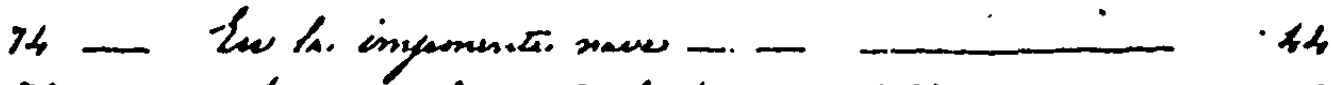

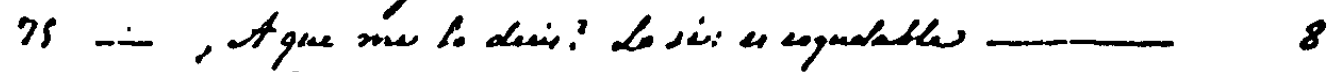

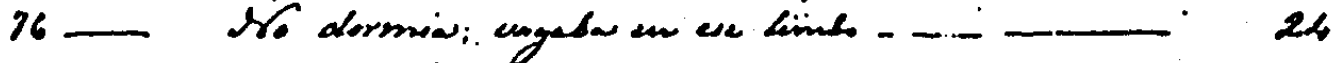

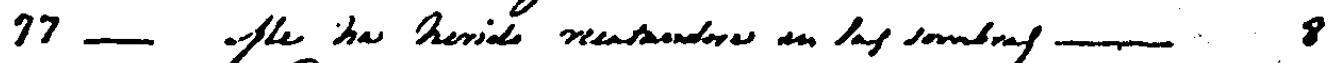

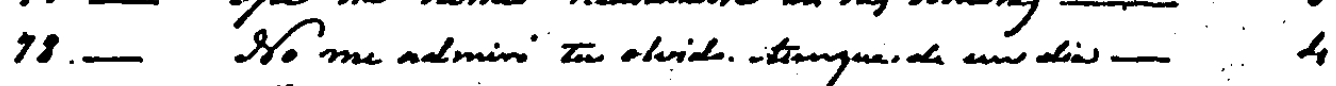

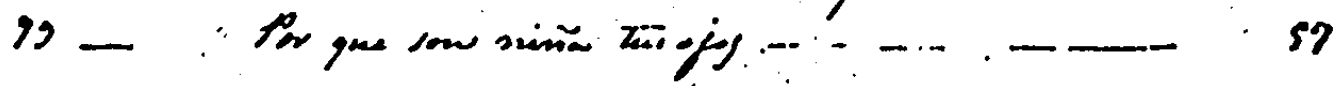


ciún poética la sido después incorporada a una obra en prosa o extraida de clla a poslcriori. Si Bécquer entresacó de sus obras prosísticas frases sucltas para reclaborarlas y darles forma poemática, hemos de admirar su talento poético, pero queclará en entredicho la espontaneidad de la composiciún.

Damos en nota la referencia bibliográfica de los libros citados en su primera mención. Lin las menciones siguientes nos limitamos a poner cl nombre del autor seguido de un número entre paréntesis que se reficre a la página en que aparece el pasaje que se comenta.

Las rimas van indicadas por el número con que figuran en la primera edición, de $187 \mathrm{I}$, publicada, como es sabido, por los amigos de Bécquer después de la muerte del poeta. Hemos decidido hacerlo así por ser, aunque imperfecta, la numeración más conocida y la que figura en la mayor parte de las numerosas ediciones de las Rimas, aunque hubiéramos preferido la numeración seguida en el manuscrito autógrafo, llamado comúnmente Libro de los gorriones, salido, al fin y al cabo, de la pluma del propio poeta o, mejor aún, la de la edición de las Rimas debida a Rafacl de Balbín y Antonio Roldán'.

Iil orden en que las poesías de Bécquer aparecen en la edición publicada por sus amigos y el seguido en el Libro de los gorriones tienen mucho de arbitrario y convencional. Ya, desde hace muchos años, los críticos se dieron cuenta de que las Rimas del gran poeta sevillano constituy'n un verdadero poema con unidad interior fácilmente perceptible si se cambia el orden de las composiciones. Esto hacen Rafael de Balbín y Antonio Roldán en su interesante edición, cuya numeración no citamos por la enorme difusión que ha logrado la numeración tradicional y el desco de dar de este modo facilidades a los posibles lectores de este trabajo.

I. a) Prosa y verso.

Lis característica en las rimas de Bécquer la brevedad de los poemas -que fueron llamados maliciosamente "suspirillos germánicos" - y la cconomía de los elementos. Resulta maravilloso y habla muy alto de la genialidad poética de Gustavo Adolfo que, con escaso número de versos, estrofas breves y poca complicación sintáctica, logre transmitir

1 Gustavo Avor, ro BícQUer, Rimas y prosas. Ediciỏn y prülogo de RAFais 
a sus lectores sus emociones de manera tan magistral. Pero el Bécquer prosista - gran artista también - es muy otro. Mucho más rico su estilo, utiliza frecuente y magistralmente el párrafo largo, usual en su tiempo.

El hecho de que en prosa se emplee el párrafo largo y la sintaxis compuesta y en verso, el párrafo corto y las oraciones simples, no es excepcional y puedc comprobarse en numerosos escritores clásicos y románticos. Muchas veces es una resultante de los límites que al poema c1l verso impone la forma métrica cuando ésta se manificsta en estrofas de pocos versos. El período en verso largo y elocuente puede darse en la amplia silva: compruébese, por ejemplo, en las poeslas de Quintana. Pero, cuando el poema está dividido en estrofas de escaso núınero de versos, el poeta tiende, en general, a clar a cada estrofa unidad de sentido y, para ello, simplifica la sintaxis y elude la complicación de las oraciones compuestas. Ello es más evidente cuanto más breves son los versos de que se compone la estrofa; es decir, que una cuarteta de versos octosílabos tiene forzcsamente que presentar una sintaxis más simple que una octava real o un serventesio en alejandrinos. Compárense, por ejemplo, unos versos de ctralquier comedia de Tirso de Molina con la cleseripción de 'loledo, de noche, que figura al principio de Los Cigarralcs y se podrá comprobar nuestra afirmación.

Iin cualquiera de las bellísimas leyendas de Bécquer o en sus otros escritos en prosa pueden hallarse fácilmente largos párrafos de sintaxis complicada, como el siguiente de El Cristo de la calavera:

IInego, poco a poco fue cesando el ruido y la animación; los vidrios de colores de las altas ojivas del palacio dejaron de brillar; atravesó por entre los apiñados grupos la última cabalgata; la gente del pueblo, a su vez, empezó a dispersarse en todas direcciones, perdiéndose entre las sombras del enmarañado laberinto de calles oscuras, estrechas y torcidas, y ya no turbaba el profundo sileucio de la noche más que el grito lejano de vela de algún guerrero, el rumor de los pasos de algún curioso que se retiraba el último, o el ruido que producian las aldabas de algunas puertas al cerrarse, cuando en lo alto de la escalinata que conducia a la plataforma del palacio apareció un caballero, el cual, después de tender la vista a todos los lados como buscando a alguien que debía esperarle, descendió lentamente liasta la cuesta del alcázar, por la que se dirigió hacia el Zocodover."

11: Bal,bíN-ANTonio Roldín. Madrid, Rialp, I969. En pp. ig a $2 \mathrm{r}$ los prologuistas incluyen wua interesante tabla de correspondencias de las tres numeraciones: la primitiva de $187 \mathrm{r}$, la del manuscrito autógrafo y la de su edición, que incluye ocho composiciones más. Por cierto, es curioso observar que la traclicional es la unica en que se utiliza la numeración romana.

İn su último libro sobre el gran lírico sevillano titulado Poética becqueriana (Madrid, Prensa Iispañola, 1969) RAIATI, DE BAI,BfN estudia en Bécquer el tránsito del acto poético al signo poemático, con amplia visión del problema. 


\section{He aquí otro pasaje de las Carlas desde mi celda:}

"Yá chzarzado en lo más espeso y fragoso del monte, llevando del diestro la caballerla por entre sendas casi impracticables, ora por las cumbres para descuurir la salida del laberinto, ora por las honduras con la iclea de cortar terreno, nuluve vagando al azar un buen espacio de tarde hasta que, por viltino, en el fondo de una cortadura, tropecé con un pastor, el cual abrevaba su ganado cu el riachuclo que, despućs de deslizarse sobre un cauce de piedras de mil colores, salt a y se retucrce alli con un ruido particular que se oye a gran distancia, en medio del profundo silencio de la naturaleza que en aquel punto y aquella lora parece muda o dormida." (De la Carta VI).

Compárese la andadura de la sintaxis y del estilo con cualquier pasaje en verso:

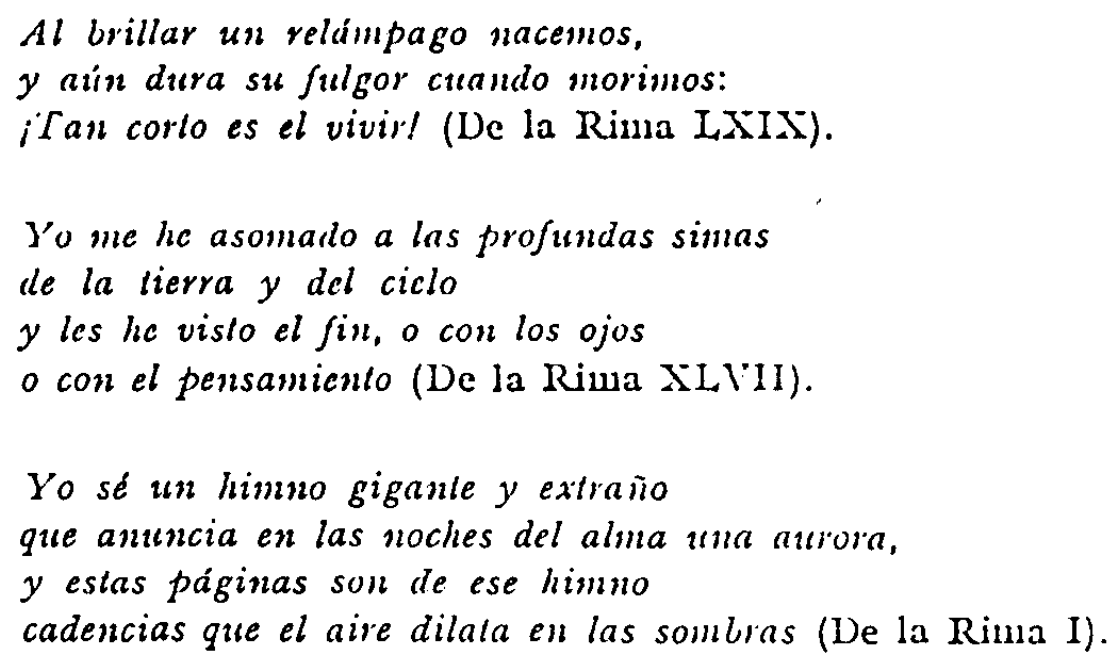

I a sobriedad del estilo y simplicidad de la sintaxis se hace más cvidente en las rimas escritas en versos cortcs:

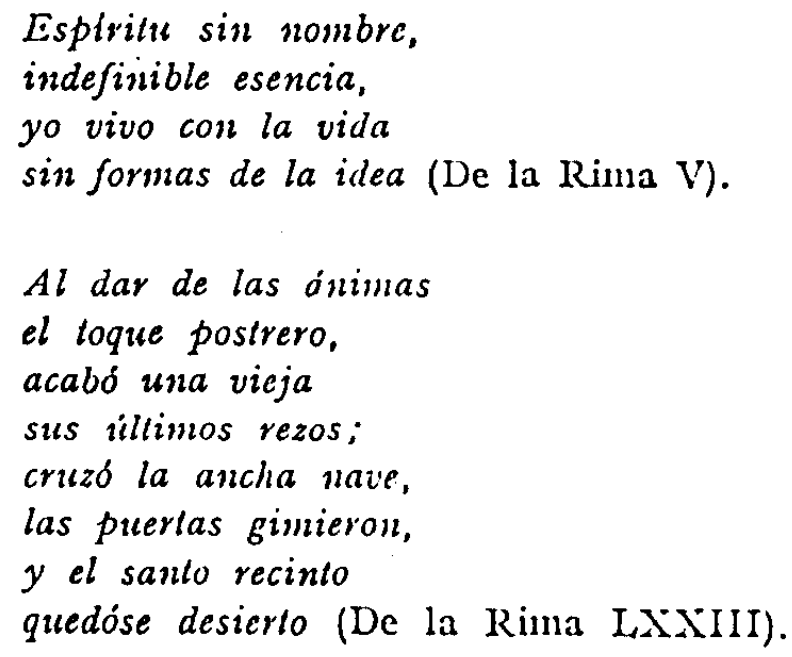


Sin embargo, solamente por influencia de la métrica no se puede explicar tan gran paso de la abundancia a la concisión, de la riqueza a la elegante desnudez - "poesía desnudan, como dijo J. R. J.- - Hay que pensar, y más si estamos convencidos de que Bécquer era un gran creador consciente de su arte y poseedor indudable de los secretos de la técnica, que estas diferencias estilísticas son intencionadas. Cuando el gran pocta sevillano, como -veremos más adelante, convicrte en poema un pasaje de una de sus obras en prosa, lejos de proceder por acumulación de elementos ornamentales procede po: eliminación para dejar solamente lo esencial poético.

\section{I. b) Los epitetos}

Gonzalo Sobejano ', en su libro El epiteto en la lírica española, dedica un capítulo al estudio de los epítetos becquerianos. Las conclusiones a que llega son las siguientes: "... La característica de Bécquer es, en este aspecto, la desuude\%, o, quizá más exactamente, la pobreza, pero una pobreza (unericla, una pobreza feliz." (39I). Iistudia los epítetos de Bécquer agrupándolos en tres secciones: epítetos tradicionales, epítetos enfáticos y epítetos subjetivos, acumulando ejemplos. "lodos estos ejenplos - termina - de un valor tan selecto y sugestivo, compensan la indudable pobreza adjetival que ofrece la lengua de Bécquer. Pero esta pobreza era un arma, indeliberadamente blandida, contra el romanticismo degenerado. $\mathrm{Y}$ de esta pobreza digna se hubiese debido alimentar la poesía española de aquella etapa, si el romanticismo no hubiese seguido fluyendo en estilos cercanos a la elocuencia o al prosaismo" (405).

No estudia en su libro Gonzalo Sobejano dos aspectos muy importantes para nosotros del epiteto en Bécquer: la comparación de los mismos en las Rimas y en las obras en prosa y la agrupación de epítetos.

Si comparamos el estilo de Bécquer en la prosa y en el verso, observaremos que, de igual modo que en la sintaxis, se produce un fenómeno de simplificación. In la prosa de Bécquer no se puede hablar, como liace Sobejano, de "pobreza digna", sino, por el contrario, de riqueza $y$ abundancia.

Basta con abrir por cualquier parte las Leyendas para hallar innumerables ejemplos de epítetos. Veamos un párrafo de El Crislo de la calavera:

1 Gonzalo Soblijano, El epileto en la llrica española, Madrid, Gredos, 1956 
1... Su contrario le imitó; pero esta vez 110 tan solo volvió a rodearlos una sombra espesisima e inpenetrable, sino que al mismo tiempo hirió sus ofdos el eco profundo de una voz misteriosa, semejante a esos largos gemidos del vendaval que parece que se queja y articula palabras al correr aprisionaclo por las torcidas, estrechias y lenchrosas calles de '́olcdo.» (Obras, I, 23I.)

J)os patsijes de las Carlas desile mi cella:

Iil anna cenagosa y sangrienta saltaba en derredor batida por sus manos, que de ve\% cn cuando se levantaban en el aire crispadas y horribles, no sé si inplorsudo piedacl, o amenazando aún en las últinas ansias.» (Obras, II, 294.)

1... se ofreció a mi vista el castillo oscuro e imponente con su alta torre del homenije... Iìn aquel castillo, que tiene por ciniento la pizarra negra de que está formado el monte, y cuyas vetustas murallas, liechas de pedruscos enormes parecen obras de titanes, es fama que las brujas de los contornos tienen sus nocturuxs conciliábulos. I,a noche habia cerrado ya, sombria y nebulosa... (Obras, 11. 295.)

l,a alumdancia de epitetos en la prosa forma contraste con la escase\% - Hosotros no diríamos pobre\%a- del verso; pero, además, en la prosa es freciente, como puede verse en los pasajes anteriores, la apariciün de parejas de epitetos (Sombra espesisima e impenetrable; castillo oscuro e imponcnte; cenagosa y sangrienta; crispadas y horribles). Listo es completamente infrecuente en el verso, aunyue aparece alguna vez como en la rima IXXXVI en que el poeta nos habla "de aquel rincón osicuro y escondidon. Más raros son los grupos de tres epítetos que aparecen en la prosa - no en el verso - como en el primer ejemplo que hemus citado, procedente de la leyenda El Crislo de la calavera, en que se liabla de "las torcidas, estrechas y tenebrosas calles de Toledo".

Agreguemos que, tanto ell el verso como ell la prosa, tiene Bécquer tendencic a colocar el epíteto pospuesto al sustantivo y no antepuesto.

\section{I. c) Correlación y paralelismo}

Deside que Dámaso Alonso publicó su estudio sobre Versos plurimimbres y' pocmas correlativos, estos artificios poéticos han sido estudiadus con insistencia en diversos poetas. No podia faltar la aplicación de esta técnica a la poesía de Bécquer, y cllo lo ha realizado Carlos Bousono en el trabajo titulado Las pluralidades paralelisticas de Bicgucr ${ }^{1}$. İsto nos evita tener que realizar anailoga indagación, ya que las

- Cakrus Bunsoño, Analisis y significaciún del paralelismo en las Rimas de Bécquer. 
conclusiones a que llega Bousoño son suficientes para nuestro trabajo.

Según Bousoño, Bécquer emplea escasamente la correlación, pero con gran abundancia el paralelisıno. «El paralelismo -escribe- da scuticlo a la organización de las siguientes composiciones: II, III, VIII, IX, XI, XII, XIII, XV, XVI, XXIII, XXIV, XXV, XXVII, NXVIII, XXXVIII, XLI, LI, LII, LIII, I,VIII, LIX, I,XI, I,XVI, I,XVII y I,XXII. lin un principio nos pasma la frecuencia de proceclimiento tan matemático en un poeta esencialmente emotivo, cono Bécquer. De las 76 rimas de la primera edición, nada menos que 25 utilizan el sistema de los paralclismos; cinco más, el de las correlaciones; dos de ellas, con paralelismos también. En consecuencia, 28 rimas están afectadas por el fenómeno de los conjuntos semejantes. Pero pronto nos percatamos de que la técnica de los paralelismos no perjudica la posible emotividad del poema. Sucede todo lo contrario: el sistema paralelístico es uno de los medios que Bécquer utiliza para incrementar la emoción" (200).

En su estudio Bousoño distingue en Bécquer nun paralelismo meramente conceptual de un paralclismo formal», analiza el fenómeno en varias rimas y escribe en las palabras finales: "El análisis realizado sobre la rima XXVII quizá nos empañe con un leve iris la visión de Bécquer como un poeta 'a la buena de Dios'. Esa rima tal vez nos hable demasiaclo alto de un Bécquer muy conocedor de su oficio, intuitivamente si se quiere. Porque los paralelismos (y en esto se oponen quizás a la correlación) no implican una excesiva intromisión de lo racional en los dominios del arten.

Es evidente que la correlación es un procedimiento más artificioso que el paralelismo, pero también lo es que la utilización de éste como sistema no puede explicarse sino reconociéndole un carácter intencional. El paralelismo, como todos los procedimientos retóricos estudiados por los antiguos tratadistas, puede ser empleado, y lo ha sido seguramente muchas veces, de modo espontáneo e indeliberado, pero no cuanclo se convierte en sistema, como ocurre en Bécquer; entonces, hay que pensar que el poeta procede de modo intencional y que, antes de empezar a componer el poema, ha trazado, en una cuartilla o en su mente, un esquema del desarrollo paralelístico que va a dar a su composición, marcando sus diversas partes, para desarrollar, después, cada una de ellas en estrofas iguales métricamente y de análoga estructura sintáctica.

En el libro del unismo autor y Dímaso Ar.onso, Seis calas en la cxpresión literaria española, Madrid, Gredos, 1951, pp. 187-227. 
Un buen ejemplo de esta técnica es la rima LIII (tal vez la más popular de las composiciones de Gustavo Adolfo, que empieza "Volvcrán las oscuras golondrinasu). Se compone de seis estrofas, que constan, cada una de ellas, de tres endecasílabos y un verso final de siete sílabas, I.as seis estrofas se corresponden paralelamente en tres grupos de a dos: en los cuales la segunda estrofa se opone a lo afirmado en la primera

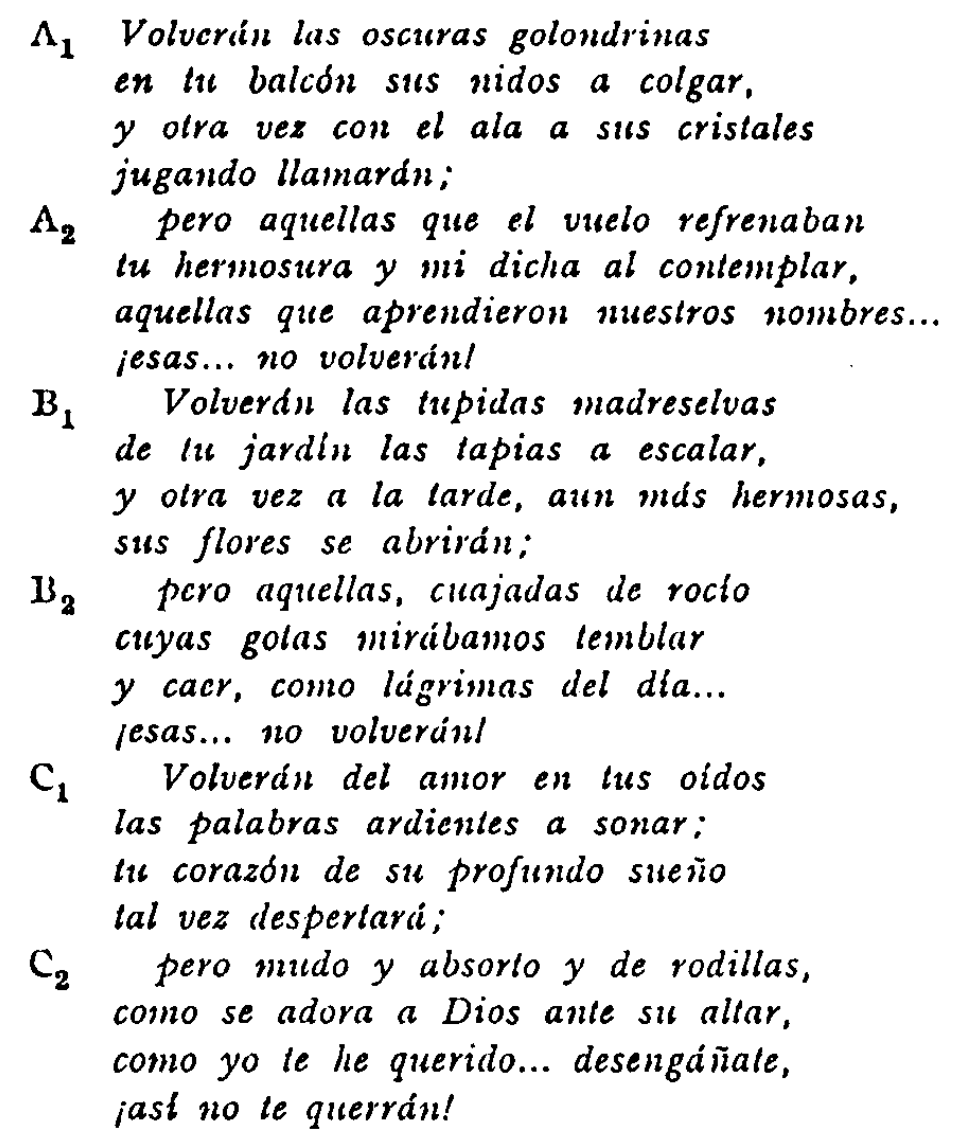

Iil esquema de la distribución de la materia es el siguiente: $\mathrm{A} / \mathrm{1}, \mathrm{A} / 2$, $\mathrm{B} / 1, \mathrm{~B} / 2, \mathrm{C} / 1, \mathrm{C} / 2 . \mathrm{E} 1$ paralelismo se ve con toda evidencia. Igual ocurre si cxaminamos la estructura sintáctica de la composición; las estrofas impares $\left(A / 1, B / 1, C_{1}\right)$ se abren con un predicado verbal que es, en los tres casos, la forma de futuro "volverán», manteniéndose en $A_{1}$ y $B_{1}$ una estructura oracional rigurosamente paralela; las estrofas pares $(A / 2$ $\mathrm{I}_{2}, \mathrm{C}_{2}$ ) se abren con el nexo "pero", que indica la oposición adversativa y se cierran con el estribillo: "Esas... no volverán». Desde el punto de vista sintáctico, las estrofas $\mathrm{C}_{1}$ y $\mathrm{C}_{2}$ presentan un paralelismo menos riguroso, lo cual parece al lector motivado por el dolor del poeta y le da la ilusión de espontaneidad, de reflejo directo del sentimiento, aunque no cabe duda de que Bécquer, antes de escribir esta rima, se trazó, o pensó al menos, un plan riguroso de la clistribución de la materia poética. 
En la rima anterior, la LII, el paralelismo es aún más exacto sobre todo en las tres primeras estrofas:

Olas gigantes $\left(A_{1}\right)$ que os rompeis bramando

en las playas desiertas $y$ remotas, $\left(B_{1}\right)$

envucllo entre la sdbana de espuma, $\left(C_{1}\right)$

illevadme con vosotrasl $\left(D_{1}\right)$

Rdfagas del huracdn $\left(\mathrm{A}_{2}\right)$, que arrebatdis

del allo bosque las marchilas hojas, $\left(\mathrm{B}_{2}\right)$

arrastrado en el ciego torbellino, $\left(\mathrm{C}_{2}\right)$

illevadn:o con vosotrasl $\left(\mathrm{D}_{2}\right)$.

Nubes de tempestad $\left(\mathrm{A}_{3}\right)$, que rompe el rayo

$y$ en fuego enciendo las sangrientas orlas, $\left(\mathrm{B}_{3}\right)$

arrebatado entre la iniebla oscura, $\left(\mathrm{C}_{3}\right)$

illevadime con vosotras! $\left(\mathrm{D}_{2}\right)$.

Llevadme $\left(\mathrm{D}_{4}\right)$, por piedad, a donde el vértigo

con la razbn me arranque la memoria...

¡Por piedad!... ¡Tengo miedo de quedarme

con mi dolor a solas!

Como se obscrvará, el paralelismo de las tres primeras estrofas es muy estricto, tanto poética como sintácticamente. En cambio, la última estrofa - aún mis que en el caso de la rima LIII - rompe dicho paralelismo para revelar de un modo desgarrador la desesperación del pocta. La estructura es sabia, y la eficacia del procedimiento, innegable.

Dámaso Alonso, en la Introducción a Seis calas en la expresión literaria española escribe, refiriéndose al tema: "¿Quién había de imaginar que las rimas de Bécquer - un gran número de ellas-, con las que tantas naturalezas humanas se han abierto hacia la más tierna sentimentalidad, estén construidas con un rigor de matemáticas correspondencias arquitecturales?" $Y$ añade: "Y muchas veces sucede que lo que parece más natural, más espontáneo, es lo más artificioson (I6).

II. Dos manuscritos autógrafos de Bécquer.

a) Manuscrito de la vima LXXIII

Además del autógrafo general de las Rimas, tantas veces citado, llamado Libro de los gorriones, se conservan aparte autógrafos independientes de las rimas LXXIII y LXXVI, que tienen singular interés 
por representar no la forma definitiva de las composiciones, sino estados intermedios de las mismas. Además, estas dos rimas son precisamente de las más importantes de la colección, por lo cual es de singular atractivo el estudio de su creación poética.

I,a rima LXXIII no es otra que la que empieza "Cerraron sus ojos" $y$ tiene forma de letrilla con el estribillo "iDios mio, qué solos / se quedan los mucrlos'n; es decir, una de las composiciones más famosas y divulgadas de Bécquer. Se conocla de antiguo la existencia de este autógrafo, ya que, cn I 886 el poeta Carlos Peñaranda, posecdor, a la sazón, del manuscrito, hizo una breve descripción de él en carta, dirigida a su amigo Kamón García Pereira, fechada en Barcelona el I de mayo de I 886 c inscrta posteriormente en el libro del mismo l'eñaranda titulado I'rosa, publicado en Manila en ISgr. Iil biógrafo de Bécquer, Juan I.úpez Núñez, recoge la referencia de Peñaranda, y de López Núñez toma lus datos José Pedro Díaz $(224,11$.) el cual, como no ha visto el manuscrito, se pregunta si éste uera un mero repertorio de rimas".

Iloy conocenos la historia del manuscrito y poseemos una minuciusa y puntual descripción del mismo gracias al interesante libro de su actual posecdor Iinrique 'loral, Hisloric de lln viejo papel ${ }^{1}$, de tall gran curiosidad como rareza, pues no se tiraron de cil más que cincuenta cjemplares numerados. La autenticidad de la transmisión del manuscrito no puede ser más completa. Bécruer se lo regaló a Narciso Campillo, el cual se lo dio a su amigo el poeta l'eñaranda, de cuya familia no ha salido ya; después de haber pertenecido al pocta y novelista José 'Toral, hoy lo posee su hijo, y nieto a su ve\% de Carlos Peñaranda, Linrique de Toral, y forma parte de su riquísima colección de autógrafos, sin duda una de las más importantes de nuestra patria.

He aqui las palabras textuales del propio Peñaranda: "Iil autógrafo, cl original de la famosa poesía, iDios mio, qui solos se quedan los muerlos!, vino a mis manos desde las del egregio poeta Campillo, albacea literario del infortunado Gustavo, y lo conservo como reliquia preciosa, a través de mis largos viajes y no escasas vicisitudes. En la oscura hoja de este papel valiosísimo, aparecen a la izquierda, en sentido perpendicular, los asonantes que se proponía emplear el escritor; después, como el balbucir de un niño, las primeras aún incorrectas estrofas, en que ya se dibujan, sin embargo, vigorosamente el sombrío y abierto nicho que espera su huésped eterno; el sepulturero impasible apoyando la tosca

- Iinkquir di Torsi, Historia de un viejo papel, Valencia, Castalia, 1954;

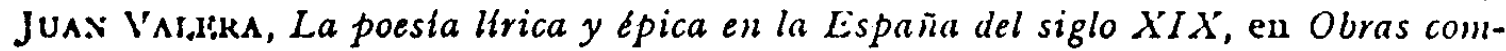
pletas, tomo XXXII, p. I77 y ss. 
mano en la siniestra piqueta; el lecho desde el que se proyecta la sombra del inmóvil cadáver, y el jayl desgarrador del vate que ve en un principio desordenadas y confusas las tristes escenas y asf las describe. A intervalos, trazados por mano febril e inquieta, pero hábil, un friso, un capitel con elegantes hojas corintias, un busto de guerrero, revestida la finisima cota milanesa y la espesa celada descansando sobre el robusto pecho; y más allá, juguetona escena de dos damas sorprendidas por paje travieso en las escalinatas del jardín, presa una de ellas en los amorosos brazos del doncel, mientras huye precipitadamente la compañera."

La lista de asonantes que figura a la izquierda del papel es la siguicnte:

Cortejo
duelo
dcudos
lastimero
huecos
sepullurero
ecos
secos
estrecho
reflejo
yerto
viejo

lïguran también, aunque tachadas, otras dos rimas:

Dieron

volvieron.

Is curioso observar que, de las doce rimas anotadas, Bécquer ha utilizado ocho, y todas entre los versos 48 a 92, lo que hace suponer que esta lista de asonantes la dispuso para que le facilitara la versificación de la segunda mitad de la rima, que tiene en total ro4 versos ${ }^{1}$.

1 Han sido utilizadas las signientes rimas (a coutinuación de cada una va el número del verso correspondiente) Corlejo (60), duelo (68), deudos (58), lastimero (56), huecos (92), sepulturero (70), estrecho (62) y yerto (48). No han sido utilizadas las rimas siguientes: esos, secos, reflejo y viejo, tal vez porque son cutre si,' clos a los, consonantes y 110 asonantes (o totales y no parciales, si se prefiere asi). Además hay, como se ha dicho antes, dos rimas tachadas: dieron y volvieron; desdeñadas, sin duda por tratarse de rimas pobres, como formas verbales análogas de escaso valor poćtico. 
Ennrique de Toral señala en su trabajo las variantes que presenta su precioso manuscrito en comparación con el texto de Bécquer en la edición príncipe y siguientes. Ein realidad, convendria tener en cuenta tres series de variantes: a) las del manuscrito Toral; b) las del Libro dc los gorriones; c) las de la edición príncipe y siguientes. Las anotamos at continuación:
V. 15 a)
V.4. 21 an 23 a)
ininúvil de vida $y$ silencio, de luz y tinieblas...
a) Ante aquel contraste

b) y c) rigida

b y c) Ante aquel contrasle de vida y mislerios. de luz y linieblas...

(A 'Toral, con razón, le parece preferible la variante de su manuscrito "toda vez que si las tinieblas son la contraposición de la luz, el silencio, representando la muerte, es la contraposición de la vida».)

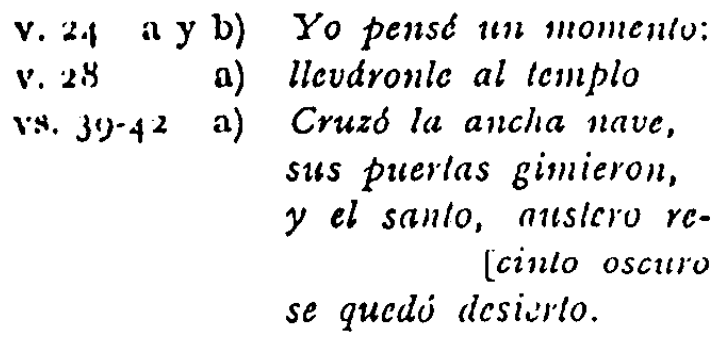

a) llevaronle al tcmplo

a) Cruzó la ancha nave, sus puevlas gimieron, y el santo, ausicro re[cinlo oscutro se quedó desirrlo.

c) Medilé un momento:

b) y c) llevironla al templo

b y c) Cruzó la ancha nave, las pucrlas gimieron y el sanlo recinlo quedóse desierto.

Iin el verso 4I cabe pensar que IBécquer acumuló adjetivos para clegir, más tarde, el más expresivo de la intuición que pretendía comunicar al lector. ¿O tal vez pensó interrumpir la uniformidad de los versos de seis sílabas intercalando alguno de diez? Si fue así, desistió del propúsito.
V. 44
a) A compais el péndulo.
b y c) Compasado el péndulo.
vs. $+7-50$
a) Tan trisle abandono,
tan alto silencio
b y c) Tan medroso y triste, lan oscuro y' jerto
llegaronme al alma, lodo se enconlraba...
$y$ pensé un momento: que pensé un momento:

('l'oral subraya la belleza y expresividad del verso 48 de su manuscrilo: "lan alto silencio».)
Vs. $57-60$
a) De lulo vestidos
amigos y deulos
pasaron cn fila
b y c) El luto en las ropas,
amigos $y$ deudos
cruzaron en fila
detrds del corlejo
formando el cortejo... 
No cabe duda de que la versión de b y c es más perfecta: "el lulo en las ropas" es expresión menos vulgar que "de luto vestidos" y, además, en la versión de a) hay una impropiedad, ya que los amigos y deudos no podían ir udetrás del corlejo», puesto que el cortejo lo formabani cllos mismos.

Las variantes de la versos $6 I-64$ son interesantes. Bécquer los escribió primero en el ms. $a$ en la siguiente forma:

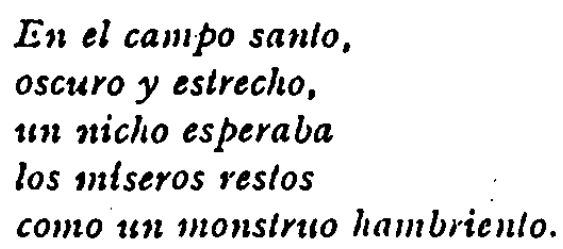

No debió quedar satisfecho Gustavo Adolfo, ya que en el mismo ms. a ensaya otra forma de expresión distinta en la que desaparece la comparación del nicho abierto con un monstruo hambriento y surge la piqueta que ha de quedar en la versión definitiva. He aquí la segunda forma del ms. a:

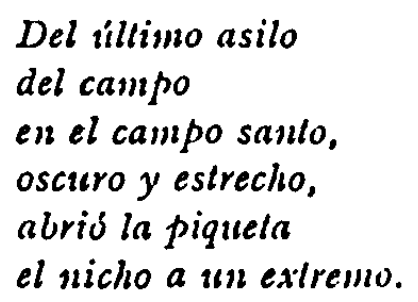

Con poca diferencia es lo que ha de quedar en $b$ y $c$ :

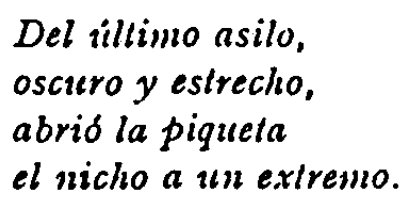

Los versos 65-68 fueron objeto de repetidos ensayos hasta llegar a un resultado próximo a la forma definitiva. He aquí los diversos intentos que aparecen en el ms. Toral:

I Algunos ladrillos y un poco de yeso cerraron la boca.

2 Con cal, -0 "in poco de arena, de agua $y^{\prime}$ de yeso cerró para siempre el fínebre hueco. 
3 Alll le dejaron de tierra cubierlo $y$ con un saludo en él le acosiaron. -o-

4 I' un poco de y'eso dei fillicbre hureco cerró para siempre el fincbre hueco.

listán aquí, entre titubeos, todos los elementos que han de aparecer en la redacción definitiva de $b$ y $c$.
Alli la acostaron.
Tapiaronle luego
y con un saludo
alespidióse el duclo.

I,os versos 69-73 también fueron objeto de muchos tanteos, como puede observarse en el ms. a): limpieza Bécquer por escribir la palabra "(luala" como instrumento del sepulturero; pero inmediatamente la taclia para cmplear la palabra "piqucla": Vs. 6y-73 a) La piquela al hombro
el sepulturero
la piquela al hombro
canlando culve dicnles
b y c) La piquela al hombro
el sepullurero.
el sepulluerro cantando entre dientes,
se fuc salisfechn
cantando entre dienles. se perdió a lo lejos.

I.os versos 73-94 no figuran en $a$. Linrique Toral, afortunado poseedor del precioso manuscrito, supone que estos versos se escribirian, quizá, en papel aparte. Sí contiene, en cambio, el manuscrito el final de la composición, es decir, los versos 95 a 104, los cuales, según puede observarse, fueron objeto de penosa elaboración. "Bécquer - escribe Toralescribiú nada menos que veintinueve versos, de los que tan sólo puclo aprovechar integramente scis». Por otra parte, tres de estos versos finales presentan versiones diferentes entre el Libro de los gorriones y las versiones impresas. Cotejamos, pues, los tres textos:

il ('rescindiendo de los versos tachados):

$$
\begin{aligned}
& \text { Lil polvo va al polvo, } \\
& \text { vucla cl polvo al polvo, } \\
& \text { vucla el alina al cielo. }
\end{aligned}
$$




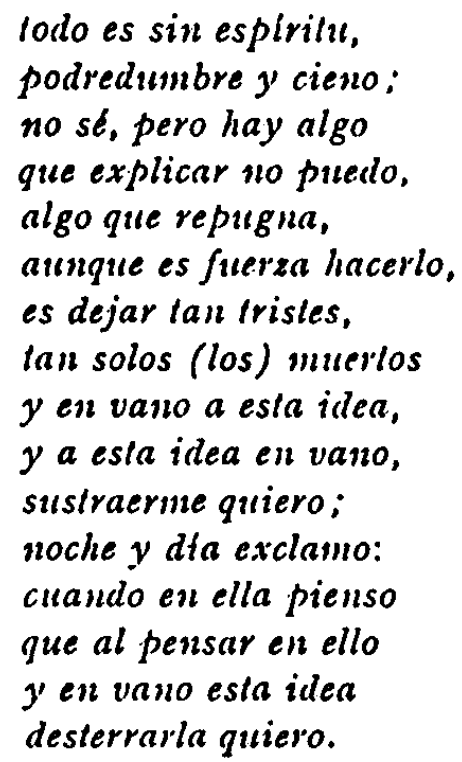

Como se ve, esto es apenas una serie de tanteos, un embrion, casi lo que los músicos y autores de cantables llaman un unonstruon. Iin el Libro de los gorriones Gustavo Adolfo ha encontrado ya la forma casi perfecta; para ello ha procedido por eliminación, suprimiendo totalmente los ocho versos finales de la anterior redacción, en los que desarrollaba cl tema de sus esfuerzos por sustraerse de la idea obsesiva del abandono en que quedan los muertos. Así llegamos a la redacción del mis. $b$, que dice así:

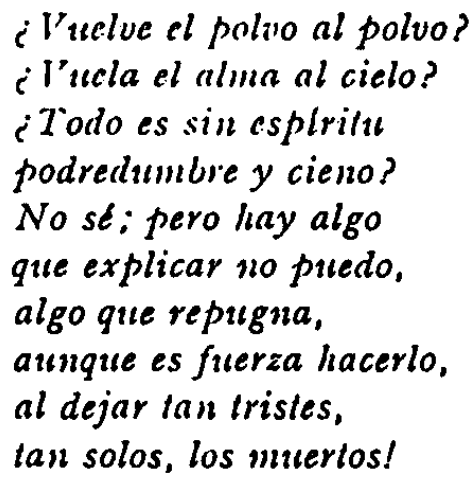

En las ediciones impresas, a partir de la primera, de estos versos hay tres totalmente cambiados; en el verso penúltimo hay, además, una pequeña variante sin importancia. El autor de estos cambios, poéticamente acertados, fue probablemente el "testamentario literario" de Bécquer, Narciso Campillo. Esta nueva y definitiva versión dice así:

¿l'uelue el polio al polvo?

¿ Viuela el alma al ciclo?

¿Toclo es vil materia 


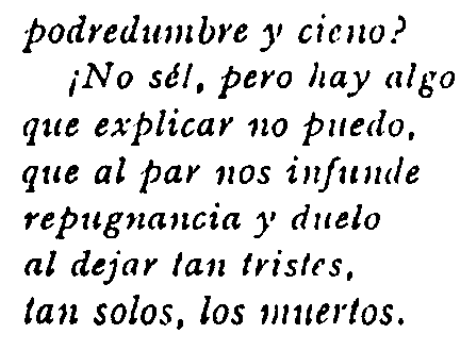

Obsćrvese un cambio importante que se realiza en los cuatro últimos versos de la rima. En toda ella el poeta viene liablando en singular, en nombre propio; pero en esta versión, que es la popularizada por las immumerables ediciones de Bécquer, la idea se ha ampliado y adquiere carícter general. Ya no es sólo el poeta, somos todos los que con él sentimos algo inexplicable y doloroso al abanclonar a los muertos en la frialdad de la última morada. Cambia así, en cierto modo, el sentido de lia composición y, por eso, es importante determinar si las variantes de csta última versión corresponden al propio Bécquer o hay que atribuirlas a Campillo, como piensa, con Dominguez Bordona, la gencralidad de los que han estudiado, desde I923, la poesía del poeta sevillano.

\section{b) Mamuscrito de la rima LXXVI}

Un interesante autógrafo de Bécquer se conserva en el MIuseo de Arte Decorativo de Buenos Aires. Se trata de una hoja de papel en que, de la fina letra del poeta, podemos leer la rima LXXVI, una de las más bellas de la colección, mas no ein el estado definitivo (como en el Libro de los gorrioncs), sino en un momento avanzado de su creación. Iisto la hace de gran interés. Anverso y reverso de la hoja han sido reproducidos, en sendas láminas, en la edición de las Rimas de la Colección Mirto (Buenos Aires, I944). El reverso, en donde, además del texto de la rima, hay interesantes dibujos, to ha reproducido también King, ya que a este investigador le ha interesado especialmente la relación cntre los dos aspectos de Bécquer: lo plástico y lo poético.

José Pedro Díaz escribe, con respecto a este manuscrito becqueriano, lo siguiente $(224,1 \mathrm{n}$.): "El dibujo, en este caso, parece haber precedido al pocman. La afirmación no es del todo exacta.

I a rima IXXVI consta de once estrofas de cuatro versos, de las cuales scis están escritas en el anverso y cinco en el reverso. Una breve descripciún por separado de cada uno de los lados del papel será muy convenicnte.

Anverso.-Contiene, como hemos dicho, seis estrofas. Las tres primeras coinciden exactamente con el texto de El libro de los gorriones, 
no presentan ninguna variante ni la menor vacilación en los rasgos caligráficos. Esto hace suponer que este papel contiene no el primer ensayo del poeta, sino una redacción intermedia que, sobre todo en su seguncla mitad, aún no es definitiva. La cuarta estrofa ya presenta variantes en los versos $\mathrm{I}, 3 \mathrm{y} 4$. (Cambio de palabras y alteración de lugar entre dos vocablos.) Las estrofas 5 y 6 van en orden distinto, preceliendo en la hoja manuscrita la 6 a la 5 . La estrofa 6 también presenta variantes de importancia. A la izquierda de las dos primeras estrofas, Bécquer ha dibujado tres pequeños rostros de mujer de perfil.

Reverso.-La estrofa 7 aparece escrita - como las del anverso- bien centrada en el papel, pero, antes de escribir la estrofa siguiente, debió ocurrírsele a Bécquer dibujar la "gótica tumba" que había inspirado la composición. El dibujo ocupa toda la parte derecha de lo restante de la hoja y otros dibujos menores se desbordan en la parte inferior invacliendo el papel. A la izquierda del dibujo principal figuran las estrofas S' y 9. Las estrofas ro y II están escritas muy apretadamente en la parte inferior y margen de la derecha. Como el pliego, al parecer, fué algo recortado, se han perdido palabras de los dos últimos versos. Existen numerosas variantes. Es interesante la del verso I de la estrofa 8 que dice "la contemplé en silencio", preferible al texto publicado "la contcmplé un momenton, ya que es más emotiva y poética.

A nuestro juicio, este autógrafo es interesante; representa un estado intermedio en la redacción de la rima y revela, por otra parte, la conocida afición de Bécquer al dibujo. Su pluma, en las pausas de la creación poética, buscaba el solaz, probablemente instintivo, o, mejor dicho, indeliberado de la interpretación plástica.

III. Concordancias entre las obras en prosa de Bécquer y algunas de sus rimas

La relación existente entre dos pasajes de las obras en prosa de Gustavo Adolfo Bécquer y otros tantos de sus rimas no pasó inadvertida al crítico americano Merchán ${ }^{1}$, hace cerca de un siglo, $y$, después, a otro americano, Francisco A. de Icaza ${ }^{2}$. Más tarde el investigador

1 Rapali. M. Mirkchis, Estudios cillicos, Bogota, 1886. Cap. Becquer y Heine, pp. 449-472. Otra edición de Madricl, Jiclitorial América, s. a.

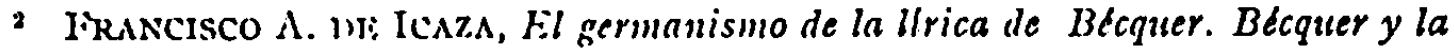
crflica. Yolletón en l:l Sol, de Madrid, 0 de septiembre de 1922. 
becqueriano Gamallo l゙̈ierros ${ }^{1}$ aumentó considerablemente el número de testimonios de esta relación existente entre el verso y la prosa del gran poeta sevillano. Por íltimo, King ${ }^{2}$ ha realizado una labor importante en lo que respecta a las concordancias entre el verso y la prosa de Bécquer.

Jis hora, a nuestro juicio, de sistematizar todas estas interesantes aportaciones. La dificultad estriba en que es de todo punto necesario fechar las obras que han de ponerse en contacto para determinar la primacía de cada una de ellas; es decir, para saber si, en cada caso, el texto ell prosa precede al texto en verso o si ha sido el opuesto el orden en que sillieron de la pluma del autor. Iiácil es comprender las dificultades de este empeño. Las obras literarias suelen ordenarse por la fecha de su publicaciún, pero éste no ha de ser forzosamente el orden en que fueron compuestas. La dificultad sube de punto tratándose de Bécquer, la mayor parte de cuyas rimas se publicaron póstumas.

\section{a) Concordancias de la rima $V$}

- Y vió el sol volteando encendido sobre ejes de oro en una atmósfera de colores y de fucgo, y eu su foco a los igneos espíritus que habitan incólumes entre las llamas, y desde su ardiente seno entonan al Criador himnos de alegria.

Vio los hilos de luz imperceptibles que atan los hombres a las estrellas, y vió cl arco iris, ccliado como un puente colosal sobre el abiswo que separa al primer clelo del segundo." (De Creed en Dios, 1862.)

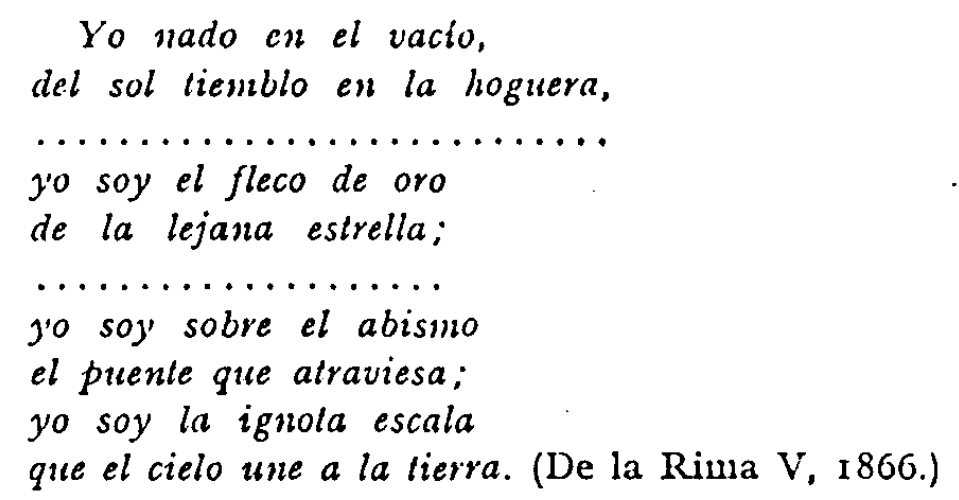

l,a evidente semejanza está en el ambiente de misterio y en a'gunas frases, en especial en la referencia al puente o escala que unen el primer cielo con el segundo, o la tierra con el cielo. A nuestro juicio, no hay

1 D. Gamal,o Iinirkos, Páginas abandonadas [de Gustavo Adotro BíclQUi:k J, Madrid, Valera, 1948. Véase especialmente el apéndice de las pp. 50 I-51 I.

- Jilmuni), I. Kin(:, Gustavo Adolfo Bécquer. From P'ainter to Poet, Aréxico, l'utria, 1953. 
interdependencia entre ambos fragmentos, sino solamente una vaga analogía. Más remotas aún son las semejanzas - que también señala Gamallo Fierros- con algunos versos de la rima III ${ }^{1}$.

\section{b) Concordancias de la rima VI}

-Quićn salse si, caprichosa como yo, amiga de la soledad y el misterio, como todas las almas soñadoras, se complace en vagar por entre las ruinas, en el silencio de la noche?" (El rayo de luna, 1862.)

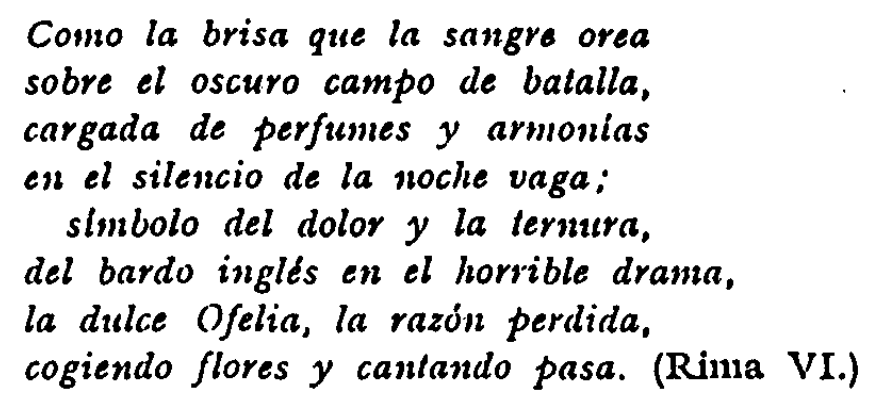

Sc trata de un pasaje de una de las mejores leyendas de Bécpuer y de la rima VI, una de las más flojas de la colección, la cual, además, tienc todo el aire de cosa fragmentaria. La semejanza es mínima. Por un lado, la mujer creada por la fantasía de Manrique; por otro lado, la dulce Ofelia, figura predilecta de Bécquer. (Recuérdese la anécdota que cuenta Rodríguez Correa en el prólogo a las Obras de su amigo; a Gustavo Adolfo, empleado en la Dirección de Bienes Nacionales, le cuesta la cesantía que el director le sorprenda dedicado a la, para él, gratísima tarea de dibujar. "Y, ¿qué es eso?" Gustavo, sin volverse, respondió: "Psch... Lista es Ofelia, que va deshojando su corona...»)

Lin realidad, la única semejanza, señalada por Gamallo Fierros, es la coincidencia de unas cuantas palabras que componen el cuarto verso de la rima: "en el silencio de la noche vaga». Muy poca cosa.

\section{c) Concordancias de la Rinna VII}

Tis la famosa rima "Del salón en el ángulo oscuro", estudiada ya repetidamente y que hasta ha servido para sugerir a Dámaso Alonso el título de la primitiva redacción de su trabajo Originalidad de Bécquer, que, cuando fue publicado por primera vez en la revista Cruz y Ray'a, se denominaba Aquella arpa de Bécquer ${ }^{2}$.

1 El importante libro de J. M. Dfez TABOADA. La mujer ideal. Aspeclos y fuchles de las Rimas de G. A. Béiquer, Madrid, C. S. I. C. 1965, señala numerosas relaciones estalisticas entre las composiciones del poeta sevillano perci no tiene en cuenta las concordancias con las obras en prosa.

- Dimaso Aronso, Originalidad de Beqquer, en Ensayos sobre poesía espanoln, Madrid, Revista de Oecidente, 1944, pp. 26r-304. 
Dámaso Alonso ha estudiado la ascendencia de la rima del arpa. -1:1 punto de partida - escribe- es Ossian y eslabones de la cadena son 'Thomas Moore, Millevoye, madame Amable Tastu y Musset." (Dámaso Alonso, según puntualiza con su acostumbrada probidad científica, utilizó algunos datos facilitados por Gamallo lierros.) Anota el catedrítico de la Universidad de Madrid la gran diferencia de valor estético quc existe entre la rima becqueriana y sus divęrsos precedentes. "iQué abismo entre la modesta comparación original y la creación poética del scvillano... Bécquer ha tomado una ingeniosa comparación varias veces expresada, y la ha hecho suya, la ha convertido en una auténtica criatura de arte!n

Casi veinte años después, King establece una nueva relación de esta rima, pero no con ningún escritor extranjero, sino con otra obra del propio Bécquer: la Introducción sinfónica que precede a la colecciún de sus obras.

IIe acjuí un párrafo de dicha Inlroducción: "Por los tenebrosos rincones de mi cerebro, acurrucados y desuudos, duermen los extravagantes hijos de mi fantasía, esperando en silencio que el arte los vista de la palabra..."

Recordemos la segunda estrofa de la rima:

¿Cuánta nota dormía en sus cuerdlus,
como el pájaro duerme en las ramas,
esperando la mano de nieve
que sabe arrancarla!'

1.a Inlroducción sinfónica está fechada en junio de IS6S y fue escrita por Bécquer de su puño y letra en el cuaderno titulado Libro de los gorrioncs. Aunque las rimas fueron escritas al final de dicho cuademo, tal vez algo después - según supone José Pedro Díaz- lo más verosímil es que, cuando el poeta trazó su Introducción sinfónica, esta rima, y la mayor parte de las demás, estaría ya compuesta. Cabe sólo scinalar la persistencia de la idea que la inspira en el espíritu de Gustavo Adolfo.

Por cierto, que en esta rima hizo una corrección desafortunada Campillo cuando fue publicada: Bécquer escribio que el arpa estaba - de su ducña tal vez olvidada»; Campillo corrigió en el manuscrito ducño y, ast se imprimió por primera vez y se sigue imprimiendo y citando, $y$ asi In aprendimos todos los devotos del gran poeta sevillano. La correccion es crrónea, porcque, en la estrofa siguiente, se habla de "la mano de nicve» 
(que sabe arráncar las notas dormidas en el arpa. Eista, por lo tanto, lia de tener una dueña y no un dueño ?. s.

d) Concordancias de la rima $X$

En el capitulo III de El caudillo de las manos rojas se intercala una canción en prosa (recordemos que se trata de una supuesta "tradición" india, que algunos tomaron por "traducción»). Esstá dialogada entre "La virgen" y "El caudillo». En ella se expresan de modo poético y delicado los efectos del amor (ensueños, acordes melodiosos, estremecimientos) cerrándose el pasaje con un brillante epifonema: "Es el amor que pasan. Con posterioridad trasladó Bécquer esta bellísima idea al verso en la rima $\mathrm{X}$. Veamos ahora los textos:

"La virgen: Tu alicnto humea y abrasa como el alicnto de un volcín; tu manc, (que busca la mía, ticmbla como la hoja ell el árbol; la sangre se agolpa en mi coratoin, reloosa en él, y enciende mis mejillas; un velo de sombras cae sobre mis pírpados; todo se horra y se confuncle ante mis ojos, que no ven más que el fuego que arde en los tuyos. Caudillo, ¿qué espiritu invisible llena el aire de melodiosos acordes y me estremece a sul contacto?

El caudillo: Virgen, es el amor que pasa." (E.l caudillo de las manos rojas, capitulo III.)

He aquí la rima $\mathrm{X}$, según la redacción del Libro de los gorriones:

Los invisibles átomos del aire
en derredor palpitan y se inflaman;
el cielo se deshace en rayos de oro;
la tierra se estremece alborozada;
oigo flotando en olas de armonia
rumor de besos y batir de alas;
mis parpados se cierran... ¿Que sucede?
iDimc... Silencio! Iis cl amor que pasa.

Cuando se publicó esta rima en la primera edición de las obras de Bécquer, apareció con una corrección en el último verso, que dice simplemente: "Es el amor quc pasa". Así la hemos leido varias generaciones de admiradores del poeta. Ira corrección, debida probablemente al amigo de Gustavo Adolfo y su "testamentario literario" Narciso Campillo, es acertada y, además, está dentro de la técnica del poeta de las Rimas,

' Un estudio muy completo de esta rima es el de J. M. Dízz Taboada, Anilisis cstillstico de la rima I'II de Bécquer. Boletin de la Sociedad Caslellonense de Cullura, 1959, XXXV, 1p. 328-33. 
que frecuentemente hace que sus composiciones finalicen con un verso mis corto que los del resto de la estrofa.

José Pedro Día\% (237) escribe lo siguiente: "I a rima $X$ repite expresiones de la leyenda "El caudillo de las manos rojas", que, como sabemos, fue publicada en 1858 . Creemos que la rima puede serle contemporánea." Nosotros nos atrevemos a aventurarnos algo más y suponemos que la rima es posterior a la leyenda, aunque sin precisar si mucho o poco. Aunque El caudillo de las manos rojas es uno de los mejores trabajos en prosa de Bécquer y, a pesar de clue está deliberadamente escrito en estilo poético, no cabe duda que la rima es de superior belle\%ar. lin realidad, el contenido de ésta corresponde solamente al final del fragmento en prosa: la pregunta de la virgen al caudillo y la breve respuesta de éste. Una posible hipótesis es que Gustavo Adolfo hubiera intentado versificar la canción incluida en la leyenda y, no habiéndole complacido el resultado del intento, decidiera dejar la referida canción cu prosa y salvara solamente la estrofa final, por su afortunada realización. Verdaderamente, y teniendo en cuenta los antecedentes y el cotejo con el texto en prosa, la rima $\mathrm{X}$ parece tener carácter fragmentario'.

\section{c) Concordancias de la rima XI}

lidmund I. King ha señalado las coincidencias entre la rima XI $y$ la leyenda becqueriana El gnomo. Realiza también un cotejo, a doble columna, entre la rima, que por su brevedad transcribe integramente, y los pasajes más característicos de la leyenda. La semejanza no estriba en la identidad de vocablos y metáforas, sino en el contraste - análogo en ambas:- entre las dos figuras femeninas $y$ en la final seducción de 10 misterioso.

lil asunto de la leyenda, reducido a sus rasgos esenciales, es el siguicute: (los muchachas; una de ellas, Marta, era altiva y vehemente; tenia los ojos más negros que la noche y se diria que de entre sus oscuras pestañas saltaban chispas cle fuego; tenía los cabell os crespos y oscuros. Magdalena, por el contrario, era humilcle, amante y bondadosa. "I a pupila azul de Magdalena parecía nadar en un fluido de luz dentro del cereo de oro de sus pestañas rubias». Cierto día, va n a la fuente al atar-

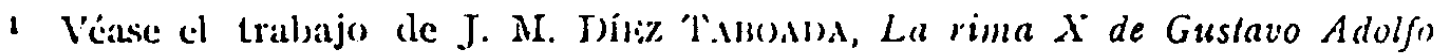

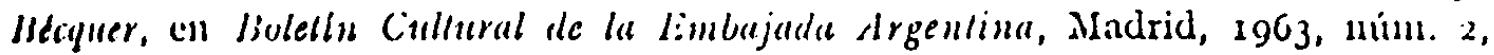
J). $5-26$. 
decer; las envuelve un ambiente misterioso que Bécquer pinta magistralmente; les hablan el agua $y$ el viento, $y$, finalmente, se les aparece un gnomo. Este "era como un hombrecillo transparente; una especie de enano de luz, semcjante a un fuego fatuon. Marta, que sigue ansiosamente al gnomo con la vista, cuando éste "se lan\%ó al fin por entre las escabrosidacles del Moncayo, como una llama que corre, agitando una cabellera de chispas, sintió una especie de atracción irresistible y siguió tras él en una carrera frenética... Magdalena tornó al lugar pálida y llena de asombro... Cuando llegó la tarde del otro día, las muchachas encontraron un cántaro roto al borcle de la fuente de la alameda. Erra el cántaro de Marta, de la cual nunca volvió a sabersen.

Esta leyenda fue publicada por Bécquer en I863. Tres años más tarde dio a la estampa en El Museo Universal la rima XI, que transcribimos integramente:

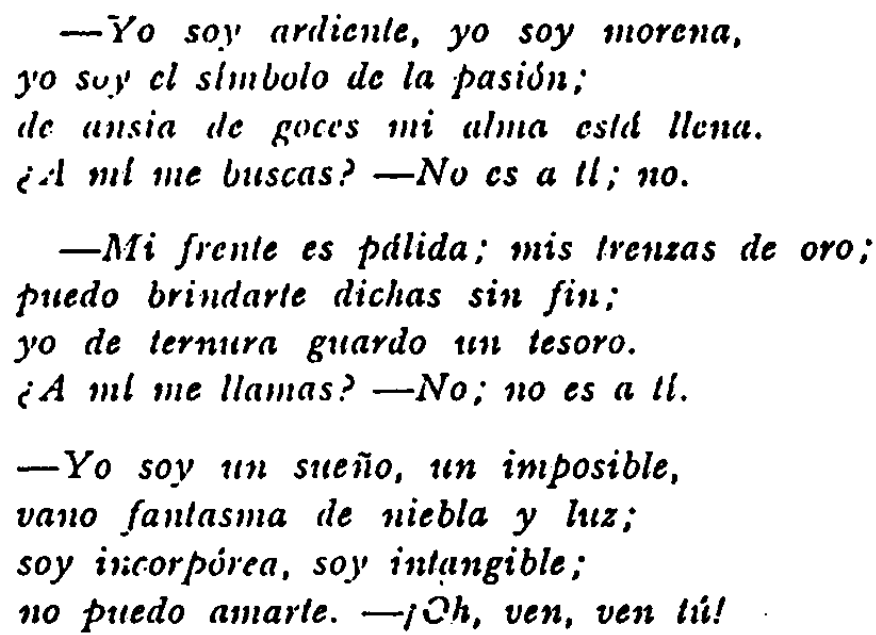

Como puede observarse, la semejanza se halla en la caracterización de las dos figuras femeninas; la una, ardiente y morena; la otra pálicla, rubia y llena de ternura. El misterio está representado en la leyencla por el gnomo y en la rima por el "vano fantasma imposible" de la tercera estrofa. La diferencia estriba en que en la leyenda el gnomo atrae a la ardiente e impetuosa morena. İn la rima hay un personaje más: el propio poeta, al que pretenden seducir tanto la morena como la rubia, a las que desdeña porque sólo siente la llamada de lo imposible y lo misterioso. Aunque la caracterización de ambos personajes femeninos sea idéntica, la situación final es muy diferente y el único denominador común que existe es el del poder de seducción de lo misterioso, lo enigmático.

King escribe: "How has Bécquer turned prose into poetry? By eliminating narrative; by describing quickly that which can be described 
(la ardiente, la morena; la pálida, la de las trenzas de oro); by eliminating time, place, and even space; by casting the three brief stanzas in the form of dialogue lean and to the point; by reducing that which camnoy be clescribed to a concisely vague metaphor (vano fantasma de nicbla y luz)." (127).

$\Lambda$ muestro juicio; la rima fue escrita después que la leyenda, como se desprende la diferencia de fecha de la publicación, pero la princijal semejanza entre ellas - la caracterización de las dos mujeres- no demuestra nada, ya que el contraste entre morena y rubia ha constituido siempre un verdadero tópico literario. Sin embargo, no se pueden negar ciertas semejanzas de intención y un análogo clima producido por $e^{\prime}$ ambiente de misterio. Aunque no puede asegurarse que para escribir la rima XI, Bécquer se initase a sí mismo, en el caso de que hubiera sido así, es interesante ver cómo elimina el poeta todos los elementos narrativos y materiales, todos los elementos concretos de la leyenda para reducir el poema solamente a la línea esencial con arte depurado y eterio ${ }^{1}$.

\title{
f) Concordancias de la rima XIII
}

I.a rima XIII es la más antigua de fecha conocida, pues se publicó en El Ncne en r859. Al transcribirla Bécquer en el Libro de los gorrioncs, introclujo importantes variantes que es preciso tener en cuenta. Gamallo lïierros, a quien los amigos de Bécquer hemos de agradecer que haya restablecido el texto íntegro de El caudillo de las manos rojas, scĩala coincidencias de expresión entre esta leyenda y la rima XIII, relac:onando las palabras "pupila", "azul", "húmeda", "punto luminoso" y "estrella". Se trata no de una copia, sino de un modo de expresión favorito de Bécquer. He aquí los textos, tal como los presenta Gamallo licrros:

•y en su pupila húmeda, azul y dilatada, brilla un punto luminoso, semcjante al reflejo de una estrella en el lagon (Eil caudillo de las manos rojas, cap. III, XI).

\author{
Tu pupila es azul, y si en su átomo \\ de luz radia una idea, \\ me parece en el cielo del crepiisculo \\ una perdida estrella! (Rina XIII, publicada en El Nene, \\ [estrofa tercera, 17-XII-1859-)
}

1 Un interesante estudio completo de esta rima es el clel malogrado profesor R. Iisqui:r Torris, Análisis estilistico de la rima XI de Gustavo Adolfo Bécquer, cu el Boldin de la Sociedad Caslcllonense de Cultura, r954, XXX, pp. 183-19z. 
ren tus pupilas húmedas y azules como el cielo de la noclee brillaba un punto de luz...* (Cartas literarias a una mujer. Carta primera, 20-XII-60.)

ren el fondo del sombrio cerco de sus ojos brillaba el punto de luz de su ardiente pupila, como una estrella en cl cielo de una noche oscuran. (La rosa de pasion, 24-III-64).

Tu pupila es azul y' si on su fondo comn "nn punto de luz radia una idea, me parece en el cielo de la tardo una perdida estrella!

(Rima XIII. Versión definitiva en el Libro de los gorrioncs, indudablemente superior a la versión primitiva. Bécquer ha tenido el acierto de cambiar en los versos impares los finales esdrújulos ("átomon, "crepiisculon) por finales llanos, y aunque tuvo que sacrificar una palabra que le era muy grata - sálomon- la sustituyó por otro sintagma de su predilección: "punto de luz».

Estos textos que ha reunido pácientemente Gamallo Fierros pueden fáci!mente ser aumentados, porque en Bécquer constituye un tipo predilecto de expresion el elogio de los ojos a\%ules, hímedos, brillantes, con chispas de lu\%. Veamos, por ejemplo en la rima XXVII:

Despierla, miras, y al mirar hus ojos

himedos resplandecen

como la onda azul, en culya cresta

chispeando el sol hiere.

g) Concordancias de la Rima XIV.

Ein Igr4, en su tesis doctoral, atribuy'ó Schneider a Gustavo Adolfo Bécquer varios relatos en prosa aparecidos como anónimos en El Conlcmporíneo; treinta y cuatro años después los dio a la estampa Gamallo liierros. Eintre ellos, una narración en prosa titulada $U n$ boceto del natural, que es indudablemente de Bécquer. Por si no bastaran otras analogías de estilo, Gamallo Fierros ha relacionado uno de sus pasajes con la rima XIV. He aquí los textos:

Describe el autor a Julia, mujer morena, de ojos pardos, inmensos y de insistente mirada. "Bajé la mirada, pero aquellos dos ojos, tan claros y tan grandes, desasidos del rostro a que pertenecían, me pareció que se quedaban solos y flotando en el aire ante mi vista, como después de mirar al sol se quedan flotando por largo tiempo unas manchas de colores ribeteadas de luz." (De Un boccto del natural, 1863.) 
No puede ser mayor la semejanza con la rima XIV:

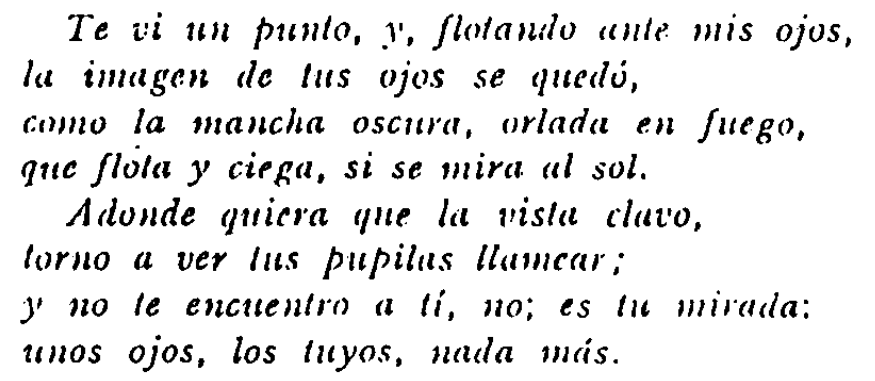

La tercera estrofa contiene una expresión tan inpropia como caracterís'ica:

\footnotetext{
De mi alcobn en el ángulo los miro, desasidos, fanlásticos lucir; cuando duermo los siento quc se ciernen de par en par abierlos sobre mit.
}

Iin Un boccio del natural ya había escrito biecquer, que los ojos estaban "desasidos del rostro a que pertenceian", expresión que repite en la rina XIV y que constituye evidente impropiedad, ya que los ojos no pucden asirse ni desasirse; aunque pueda parecernos que están separados, exentos, apartados del rostro, nunca podrán estar clesasidos. - Pero, al parecer, a Bécquer le gustó la cxpresión y la reitera al exponer la idea ell forma métrica.

La rima XIV fue incluida en el Libro de los gorriones en IS6S; no hay noticia de que fuera publicada antes. Parece claro que la rima es posterior al relato en prosa. Bécquer, utilizando una vez más una técnica que ya hemos visto empleada otras veces, transforma en poema un breve pasaje de una obra en prosa, si le seduce por su valor metafórico, por su originalidad, su brillantez o cualquier otra cualidad que le atraiga. Pero aquí la elaboración fue mayor que en otros casos, porque Gustavo Adolfo no se linitó a expresar en forma métrica la seducción de unos ojos enormes que, al contemplarlos, le parecían "desasidos" del rostro. La estrofa final cierra el poema elevándolo a mayor altura bajo el signo de la fatalidad:

Yo se que hay fuegos faluos que en la noche llevan al caminanle a perecer: yo me sienlo arrastrado por lits ojos, pero a donde me arrastran, no lo sé. 
La magia del creador ha convertido un pasaje de una obra en prosa en un bello poema.

\section{1) Concordancias de la rima $X X I$}

-lin mua ocasión ne preguntaste: - ¿Qué es la poesia? ¿'le acuerdas? Mis ojos... se volvieron instintivanente hacia los tuyos y exclance, al fin: Ia poesia... la poesia eres tii." (De la primera de las Carlas literarias a una mujer, 20 de dicicumbre de 1860.$)$

Rima XXI:

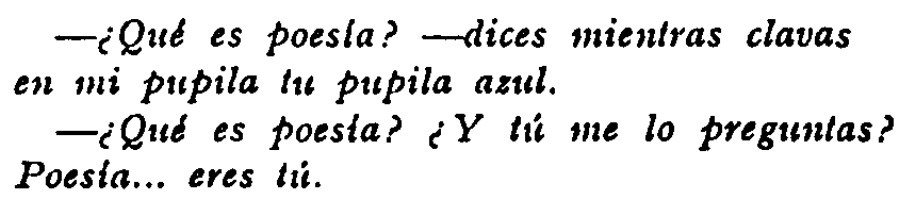

No se conoce la fecha en que Bécquer compuso esta rima tan breve como fumosa. Por su evidente coincidencia con el pasaje anteriormente transcrito de las Cartas literarias a una minjer, aunque Schneider la fecha en IS68, José Pedro Díaz la sitúa hacia I860, suponiendo a ambas producciones con escasa diferencia de tiempo entre sí en el instante de sll creación.

Quien primero señaló la obvia semejanza entre ambos textos fue Merchán, al que siguieron, con gran diferencia de fecha, Icaza y Gamallo Iiierros. Ya hemos indicado que la semejanza es evidente, pero está exagerada por el hecho de haber sido transcrito el texto en prosa truilcado e incompleto. Adquiere así análoga brevedad a la que existe en el texto en verso, imitando su concisión esencial. Pero este efecto está conseguido no por Bécquer, sino por los críticos que, con objeto de aumentar la semejanza entre ambos pasajes o por economía de espacio, han reproducido el texto ell prosa enormemente cercenado.

Conviene, pues, transcribir el principio de la primera de las Carlas lilerarias a una mujer en toda su integridad. Es así:

"lin uma ocasión me preguntaste: - ¿Qué es la poesía?

¿Te acuerdas? No sé a qué propúsito habla yo hablado algunos momentos antes de mi pasión por ella.

¿Qué es la poesia?, me dijiste; y yo, que no soy muy fuerte en esto de las definiciones, te respondi titubeando: la poesia es..., es... y sin concluir la frase buscaba inutilmente en mi memoria un térnino de comparación, que no acertaba a encontrar.

Tí habias adelantado un poco la cabeza para escuchar mejor mis palabras; los negros rizos de tus cabellos, esos cabellos que tan bien sabes dejar a su an- 
tojo sombrear tu frente con un abandono tan artistico, pendian de tu sien y bajaban rozando tu mejilla hasta clescnusar en tu seno; en tus pupilas, humedas $y$ nzules como el cielo de la noclic, brillaba un punto de luz, y tus labios se entreabrlan ligeramente al impulso de una respiración perfumada $y$ suave.

Nis ojos, clue, a efecto, sin ducla, cle la turbación que experimentaba, habian crrulo un. instante sin fijarse en ningún sitio, se volvicron instintivanente lacia lus tuyos, y exclamí al fin: la pocsia... jla poesía eres tú!

'le acucrdas? (Obras, tomo III, pp. 85-86.)

Iin el texto integro cobra importancia extraordinaria la descripción de la mujer; Bécquer se la recreado en dibujar su actitud, su gesto $y$ en detallar sus perfeccioncs. La resp)uesta del poeta ("la poesía eres tuil) carece de la desnuda economía verbal de los cuatro famosos versos.

I.a morosidad con que está dibujada la escena hace pensar que no se trata de una ficción imaginada, sino de cosa vivida. La mujer fija en el poeta la pupila azul, y este color podría ser impuesto por exigencias de la rima (azul, tii), pero esta razón no existe en la versión cn prosa y por clla sabemos que la protagonista de tan poética anécdota era una inujer de cabellos negros y ojos azules, combinación tan peligrosa como infrecuente. 'Jodo lleva a pensar en Lilisa Guillén, el gran amor de Gustavo $\Lambda$ dolfo, y a situar la escena poco antes del dolorcso rompiniento yue probablemente llevó a Bécquer al matrimonio precipitado con Casta Isteban en mayo de ISGr. O tal vez en la propia Casta y en los días de noviazgo apasionalo como piensa Heliodoro Carpintero.

Otras diferencias estilisticas hay entre ambos textos; en prosa se usa el pretérito; en verso, el presente que actualiza más la escena. Lin prosa se habla de "las pupilas", en verso de "la pupila" (la pupila azul) tipo de sinécdoque no infrecuente en el autor de las Rimas del uso del singular por el plural. (Pupila, por pupilas; labio, por labios) ("y en mi labio una frase de perdónı). La versión ell verso es más bella que la versión el prosa si descartamos de ésta la extensa parte descriptiva y dejamos sólo para el cotejo las frases fundamentales.

Que inspirase las Carlas litcrarias Elisa Guillén o Casta Esteban importa poco a nuestro propósito. Lo cierto es que Bécquer evocó una escena real con una bella mujer morena de ojos azules. Parece lógico yue la carta primera fuese inmediatamente posterior al momentu vivido, cu cuyo recuerdo se deleita el poeta.

Jusé Pedro Díaz, en dos lugares de su importante libro, llama a la carta "comentario" de la rima - no de un modo terminante, ciertamente-, lo yue hace suponer que, a su parecer, la rima precedió a la carta. Is difícil llegar a una convicción plena. Nos inclinamos, sin ninguna seguridad, a la solución opuesta. A raiz de producirse el hecho, Bécquer 
lo comenta y glosa en la primera de sus Cartas literarias a una minjer, y sólo más tarde se da cuenta de que la frase esencial la poesía eres tú), desgajada de todo lo accesorio -descripción de la escena; filosofía de la poesía y del amor- podía convertirse en bellisimo madrigal literario de sólo cuatro versos. Es decir, yue la rima no es germen de la carta, sino, por el contrario, una vuelta a lo esencial poético, a esa poesía desnuda que placía a Juan Ramón Jiménez.

\section{i) Concordancias de la rima $X X X I V$}

I a rima dXXIV se relaciona con el trabajo en prosa de Bécquer titulado Un bocelo del natural, publicado en 1863 en El Contcmporáneo, sin firma, identificado como de Gustavo Adolfo, por Schneider en rgr 4 y clado a la estampa, finalmente, por Gamallo Fierros en r948. En cuanto a la rima XXXIV no fue publicacla hasta la aparición de las Obras, de Bécquer, y la única referencia cronológica que poseemos es yue cstaba compuesta en I 868 , ya que en esa fecha la incluyó el autor en el manuscrito autógrafo conocido por Libro de los gorriones.

Iiue schneider el primero que relacionó $U n$ boceto del natural con la rima $\mathrm{X} X \mathrm{x} I \mathrm{~V}$. A diferencia de lo que sucede en otros casos, la relación entre ambos textos no estriba en la común utilización de comparaciones, imaigeneś, metáforas, epitetos o formas de expresión, sino en la coincidencia de los temas, salvando la distancia que ha de existir forzosamente entre una narración novelesca cn prosa, en que el tema se convierte o desarrolla en forma argumental, y un poema lírico en el que las referencias al asunto son siempre mucho menos concretas.

Un boceto al natural está escrito en primera persona. El autor nos relata la curiosidad que despertó en él, hallánclose durante el verano en un puerto de mar, la llegada de Julia, mujer que se le antoja enigmática, prima de unas amigas suyas. Julia, mujer de gran belleza, de ojos inmensos y profundos,es, asimismo, de muy pocas palabras $y$ en estas pocas revela gran vulgaridad. I a obsesión que va apoderándose del autor, intrigado por aquella extraña mujer, le incita a pedir consejo a I,uisa, prima de Julia, y ésta le aconseja que no se enamore. "Pero lo que yo deseo que me explique -insiste el narrador- es por qué parece que nos desdeña, por qué guarda ese silencio misterioso." Luisa le responde que, sencillamente, porque la mamá de Julia, que era una mujer muy inteligente, se lo había prohibido $y$, ante la sorpresa del galán, y cerciorándose de que no podían oírla, dijo bajando la voz: „Porque es tonta.» 
'I'odo lo enigmático y misterioso de aquella bella mujer no era sino precaución y recelo de clemostrar su tontería. Así termina, el relato, con un final abrupto y sin que conozcamos la reacción del incipiente cuamorado.

La rima XXXIV, de mucha más calidad literaria, se compone de cinco estrofas de cuatro versos endecasílabos, a excepción del segundo de cada cstrofa, yue solinncnte tiene sicte sílabas. Cada una de las tres primeras estrofas está dedicada a cantar las perfecciones de una nuujer en la siguiente forma:

listrofa r.a Armonía de los movimientos.

Iistrofa 2.a Lincanto de los ojos.

Listrofa $3 .^{a}$ Belleza de la risa y el llanto.

La estrofa $4{ }^{a}$ resume, en cierto modo, 10 que se dice en las tres anteriores:

\author{
Lilla tiene la luz, tienc el perfume, \\ cl color y la linea, \\ la forma, engenilradora de desens, \\ la cxpresión, fuente elerna de pocsia.
}

Ia estrofa final nos informa de que aquel dechado de perfecciones, como la Julia del relato en prosa, es tonta, o, más exactamente, cstúpida. Pero ahora nos enteramos de algo más, de que al poeta no le importa su estupide\% mientras la disimule con el silencio. Final un poco despectivo y amargo:

¿Quć es cslipida?... iBah!, mientras callando,
guarde oscuro el enigma,
siempre valdrá, a mi ver, lo que ella calla
mis que lo que cualquicra otra me diga.

lil mismo tema en forma de narración en prosa y de poema lírico en verso. La realización en verso, seguramente posterior, mucho más perfecta.

\title{
j) Concordancias de la rima $X L V$
}

lista rima ha sido relacionada con varios textos en prosa. I,os enumeraremos cronologicanente.

1) .... los cardos silvestres y las ortigas brotaban en medio de los cnarenados caminos, y en los trozos de fábrica próximos a desplomarse, como el penacho de una cimera, y las campanillas blancas y azules, balanceánclose como en un columpio solure stis largos y flexibles tallos, pregouaban la victoria de la clestrucción $y$ de la ruina. (E:l rayo de luna, I-2-I [-62.) 
B) .... el jaramago, que con sus grupos de flores amarillentas ondula como el penacho de una cimera sobre los muros." (Historia de los templos de España, 3-IX-62.) (Gamallo Fierros da la fecha anterior que es la de la publicación en El Contemporáneo de la descripción de la basilica toledana de Santa Ieocaclia, a la que pertenecen las líneas anteriores.)

C) a... lin su clave liay un escudo, roto ya y carcomido por la acción (le los años, en el cual crece la yedra, que agitada con el aire, flota sobre el casco que lo corona conno un penacho de plumas." (Tres fechas, i 802.$)$

D) Wigúrense ustedes un medio punto de piedra carcomida y tostada en cuya clave luce un escudo con un casco que en vez de plumas tiene en la cimera una pomposa mata de jaramagos amarillos nacida entre las hendiduras de los sillares." (Carlas desde mi celda, 1864.)

\title{
E) Rima XI,V:
}

\author{
En la clave del arco ruinoso, \\ culyas piedras el tiempo enrojecib. \\ obra de un cincel rudo, campeaba \\ el gótico blasón. \\ Penacho de su yelmo de granito. \\ la hiedra que colgaba en derredor \\ daba sombra al esciulo, en que una mano \\ lenla un corazón...
}

(Con respecto a la fecha de los anteriores versos sólo sabemos que en IS6S fueron incluidos por Bécquer en el Libro de los gorriones, desconociéndose totalmente la fecha de la composición de los mismos.)

Quien primero señaló la similitud de los pasajes C y Ii fue el crítico cubano Rafael Merchán en el libro anteriormente citado. Gamallo liierros recoge todos los pasajes, aunque colocándolos en orden diferente (E, C, D, B, A); su intención fue sólo, al parecer, la de reunir los testimonios y no la de ordenarlos cronológicamente. El orden cronológico que hemos intentado nos da cierta luz, pese a la inseguridad de algunos de los datos.

La imagen que suscita en Gustavo Adolfo la contemplación de la vegetación parásita en las ruinas venerables es persistente, acude con rciteración a su memoria y se va perfeccionando cada vez más hasta culminar en su famosa Rima. Al principio se trata sólo de los jaramagos flotanclo sobre viejos muros como el penacho de una cimera, pero, después, comprende que la imagen es más bella y exacta colocanclo el penacho silvestre sobre un escudo mejor que sobre un muro. En Tres fechas sustituye los jaramagos por la yedra, aunque vuelve a aquellos en las Cartas desde mi celda, evidentemente escritas con posterioridad. Al componer la Rima torna a la yedra y la hace colgar dando sombra al 
escudo. Conserva los elementos anteriores, como la idea de ruinas (Bécquer escribió "arco ruinoso", aunque Campillo corrigió - sim duda para evitar el hiato- "arco mal seguron) y el color rojizo de la piedra dorada por el tiempo; pero, aliora, lia sido eliminado el signo de comparación "como" y' la imagen se ha converticlo en una verdadera metáfora. "l" $c$ muchom ess la primera palabra de la estrofa, presentándonos la imagen descle el primer momento con verdadera eficacia poética.

Por otra parte, lo que en los anteriores textos es sólo un cletalle descriptivo, ahora se convierte en parte esencial de la composición. lil arco ruinoso y en su clave un escudo, cuyo yelmo ostenta un penacho de yedra; y en el escudo, una mano que sujeta un corazón. Lil pocma prosigue:

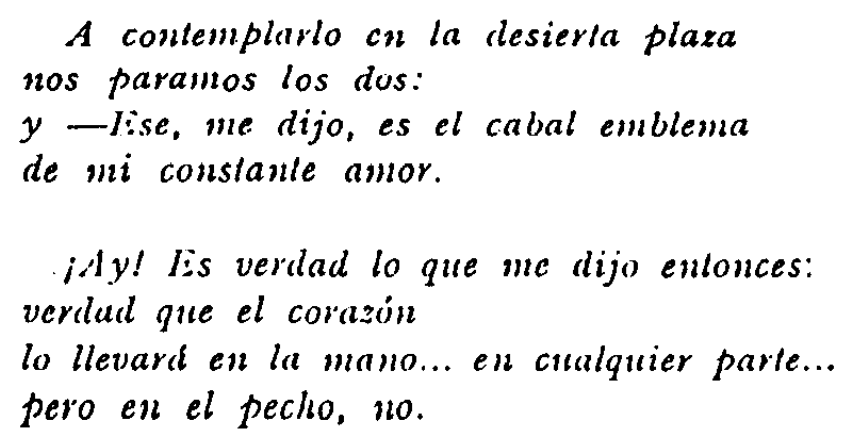

Cuatro breves estrofas. Las dos primeras, con la metáfora tan lentamente elaborada del penacho de yedra y la descripción del escudo con el cmblema del corazón en la mano, preparan el breve relato de la tercera estrofa y el amargo sarcasmo de la estrofa final. La lectura atenta de los anteriores textos ordenados cronológicamente creemos que 110 permite dudar de que la rima XLV, en su parte descriptiva, representa el final de un largo camino que antes ha ido realizando el poeta al través de sus obras en prosa.

k) Concordancias de la rima LXXIV

King ha señalado la coincidencia temática entre la famosa leyenda Tres fechas y la rima LXXIV, publicando los textos a doble columna.

lin la redacción en prosa se señalan en cursiva las palabras e inágenes coincidentes con las del texto versificado.

se trata de la ceremonia de la profesión de una monja. Lil poeta, después de describir la fábrica renacentista de una iglesia, se aproxima a las dobles rejas que protegen la clausura y ve, confusamente, a 
las monjas con sus hábitos blancos. El poeta estaba sobrecogido; le parecía contemplar algo sobrenatural. La nueva monja traspasa la puerta claustral que se cierra para siempre.

Veamos algunos fragmentos de la redacción en prosa:

Iil altar mayor estalja colocado en el fondo, bajo una cúpula de estilo del Renaciniento, cuajada de angelones con molduras y florones doraclos... Yo tanbién ne cnc:anninć hacia açuel sitio con objeto de asomarme a las dobles rejas que lo separaban del templo... Como unos fantasmas blancos y negros que se movian entre las tinieblas... se adivinaban, veladas por la oscuridad, las confusas formas de las religiosas... Hasta aquel momento no pude clistinguir entre las otras formas confusas cuál cra la de la virgen que iba a consagrarse al Señor..., parece una mujer que se mueve y anda y deja volar su traje al andar, ya un velo blanco... ya uu fantasma que se eleva en el aire... Una alucinación de ese género experimenté yo al mirar adelantarse hacia la reja, como desasiéndose del fonclo tenebroso del coro, aquella figura blanca y ligerisima... El resplandor de torlas las luces la iluminó de pronto y pude verla el rostro... Yo estaba conmovido; no, commovido no, aterrado. Creia presenciar una cosa sobrenatural... Di dos pasos adelante, (quise llamarla, quise gritar, no sé, me acometió un vértigo..., pero en aquel instilutc la puerta clanstral se cerró... para siempre... lil esposo mistico aguardaba a su esposa. ¿Dónde? Mis allá de la muerte... (Tres fechas, i 862.)

Iil poema está dividido en cinco estrofos. Ein la primera, Bécquer convierte a los angelones que en el relato en prosa figuran en la cúpula, ell guardianes simbólicos de la clausura y para eso los sitúa en la puerta; la descripción que hace Bécquer conviene más que a figuras de ángeles a las de arcángeles, tal como los han representado los escultores barrocos, con espadas desnudas y vestiduras flotantes con paños muy movidos, como agitados por el viento.

\section{Estrofa I. Las ropas desceñidas, desnudas las espadas, en el dintel de oro de la puerta dos dingeles velaban.}

Ein la segunda estrofa el poeta se ve detenido por las férreas rejas que defienden la clausura:

listrofa 2. Me aproximé a los hierros que defienden la entrada, $y$ de las dobles rejas en el fondo la vi confusa y blanca.

I. a tercera estrofa refleja el clima de ensueño y de misterio característico de la pocsia becqueriana: 


$$
\begin{aligned}
& \text { Listrofa 3. La vi como la imagen } \\
& \text { que en un ensue ño pasa, } \\
& \text { cono un rayo de luz tenue y difuso } \\
& \text { que entre tinieblas nada. }
\end{aligned}
$$

I.a estrofa cuarta expresa la atracción que experimenta el poeta:

$$
\begin{aligned}
& \text { Iistrofa 4. Me senti de un ardiente } \\
& \text { deseo llena el alma: } \\
& \text { iComo atrae un abismo, aquel misterio } \\
& \text { hacia st me arrastraba! }
\end{aligned}
$$

lin la quinta y última estrofa la perfecta y sabia arquitectura del pocma nos trae de nuevo a los ángeles (o arcángeles) que custodian la pucrta tras la cual moran las esposas del Señor.

\section{Listrofa 5. iMás ay! que de los ángeles parecian decirme las miradas: - El umbral de esa puerta isólo Dios lo traspasal}

$A$ nuestro juicio, el cotejo de estos dos pasajes es enormemente revelador de la manera de componer de Gustavo Adolfo. La escena presencinda, vivida, de la profesión religiosa de una monja de clausura debió inpresionarle vivamente, sin que para ello sea necesario atribuirle ningún interés de tipo personal, ni achacarle una pasión amorosa inćdita. Bastaba con el ambiente del templo, la belleza arquitectónica y escultúrica a que su espíritu de artista era tan sensible; las luces, la musica, las preces y, por encima de todo, el misterio de la clausura y cl scntido de determinación definitiva, irremediable del acto. Todo ello, en la sensibilidad de Bécquer, debió producir honda impresión y su talento de escritor la plasmó primeramente en un relato poemático, en prosa, de carácter levemente novelesco para, más tarde, recrearlo en una de sus más bellas rimas. Obsérvese que el pocma en verso está sabiamente compuesto con cinco estrofas en que la materia ha sido distribuida con sabia arquitectura. El poeta ha procedido por eliminación. Ha suprimido todo lo accesorio para dejar solamente las líneas esenciales. No se dice siquiera de qué ceremonia se trata, ni la clase de interés que el poeta siente por la figura vestida de blanco que desaparece entre las sumbras definitivamente. Ia emoción, la atracción del misterio, lo es todo. I' cllo, expresado en cinco estrofas muy sencillas de cuatro versos, tres de sicte sílabas $y^{\prime}$ uno, el tercero, de once (el mismo esquema de la seguidilla gitana que liabía usado el íntimo amigo de Bécquer, Augusto 
Fierrán, aunque con versos de siete y no de seis sílabas); pero Gustavo Adolfo, para cerrar la composición y dar métricamente la impresión de que el poema termina, altera la estructura de la última estrofa, en la cual el verso endecasillabo, en vez de ser el tercero, es el segundo. Esta modificación del sistema hay que suponerla intencionada, ya que no presentaba dificultad alguna someter la última estrofa al esquema general; pero, de esta forma, la brevedad imperativa de los dos últimos versos -dos heptasílabos- cierra magistralmente la composición.

Brive nota final

Aunque, como puede deducirse de la lectura de las páginas anteriores, es difícil llegar a conclusiones terminantes, podemos, sin embargo, aventurar nuestro juicio.

En lo que se refiere a la relación entre los textos en prosa de Bécquer y algunas de las Rimas, Gamallo Fierros se inclina a pensar que la mayor parte de las coincidencias metafóricas «hubieran venido al mundo de las Letras envueltas en los finfsimos cendales de una sedosa versificación aladamente lírica». La única razón que da es que "el fenómeno de la creación en verso suele verificarse con una imprevisión genial y febril", es decir, que sigue pensando en Bécquer como en un poeta espontáneo y sin artificio. El mismo Gamallo no puede menos de reconocer que en los casos de las rimas XIII y XXI la redacción en prosa ha precedido a la versificada (5I7-8). Por su parte, King no acepta la opinión de Gamallo líierros $y$, teniendo en cuenta su gran interés por cuanto se refiere a las aficiones pictóricas de Bécquer, escribe: "In Becquer, painting turns to prose, and prose, purified of painting, turns to poetry" (90), añadiendo en nota de la misma página, que en las rimas "the process is one of elosing, contraction, condensation".

Nuestra opinión, ocioso es decirlo, se acerca más a la de King que a la de Gamallo Fierros. Por lo que se refiere a las relaciones entre verso y prosa de Bécquer, estimamos que, ell la mayor parte de los casos, la redacción en prosa precedió a la redacción en verso. Pero no todos los casos son de igual importancia. Hay coincidencias que no son otra cosa que la aparición en ambos textos de formas habituales de expresión; otras veces existe una deliberada reiteración metafórica $y$, finalmente, cn los casos más importantes, la redacción en verso es una verdadera reelaboración perfeccionada que conduce a una versión poética de major concentración. 
Hemos entrevisto un poco la técnica de composición del gran poetir $y$, si hay que abandonar la idea romántica de considerar a Gustaro Adolfo Bécquer como a poeta espontáneo, como una fuerza de la naturalcza, nuestra admiración hacia él es aún mayor si tencmos cn cuenta el esfuerzo y dolor que es necesario para esta labor de elininación y condensación en la creación poética y, sobre todo, la manera genial como sabe ocultar el esfuerzo y dejar en el lector la impresión, que viene durando un siglo, de que sus rimas son gritos espontáneos que brotan directamente del alma herida del poeta.

$$
\text { Juan antonio Tamayo }
$$

